\title{
El Círculo de Saavedra: amistad, lobby y poder de los venezolanos a finales del setecientos español, 1783-1799
}

\section{The Circle of Saavedra: Friendship, Power and Lobby at the end of the eighteenth century in Spain, 1783-1799}

\author{
Alejandro Cardozo Uzcátegui \\ Universidad Simón Bolívar, Venezuela
}

Recibido: 5-IX-2012

Aceptado: 27-XI-2012

\section{Resumen}

Francisco de Saavedra fue el segundo intendente de Venezuela en la década de los ochenta del siglo XVIII. Fue enviado por José de Gálvez para aplicar el programa ilustrado: reorganizar la Hacienda en Venezuela, llevar a cabo reformas económicas y administrativas para el desarrollo de la provincia venezolana. Rápidamente se tejió a su alrededor un poderoso círculo de los más destacados criollos caraqueños (mantuanos), quienes a su vez, pasada una década de la experiencia de Saavedra en Venezuela, enviarán a sus hijos a la corte. Allá se reactivará el círculo que Saavedra forjó años atrás en Caracas, y funcionará esta vez como un aparato eficaz de lobby cortesano para los venezolanos que hacían su Grand Tour en la corte española.

Palabras clave: Francisco de Saavedra, Ilustración, Lobby, Mantuanos, Criollos, Gran Tour, Corte española.

\begin{abstract}
Francisco de Saavedra was the second Intendente of Venezuela from 1783-1788. He was sent by Jose de Galvez to implement the program illustrated: reorganize the Treasury in Venezuela (the Hacienda), implement economic development policies and administrative for the development of the province of Venezuela. Saavedra quickly joined the most powerful aristocrats (criollos, mantuanos) in Caracas: a powerful circle around the Intendente Saavedra. Ten years later the children of these aristocrats travelling to the Spanish court and reactivate the Circle of Saavedra. Will this circle at the Spanish Court a powerful lobby of Venezuelan, making his Grand Tour.
\end{abstract}


Keywords: Francisco de Saavedra, Enlightenment, Lobby, Mantuanos, Criollos, Aristocrats Creoles, Grand Tour, Spanish Court.

\section{Francisco de Saavedra forja un lobby atlántico}

Francisco de Saavedra tenía fuertes convicciones en torno a ganarse la lealtad de la élite criolla americana. En Nueva España, como en La Habana y en Caracas hizo importantes gestos a favor de los notables locales como una forma práctica y justa de abrazar y obsequiar a unos españoles "olvidados", de "segunda" o poco confiables. Sensibilidades todas a flor de piel a finales del setecientos en la América española. Francisco de Saavedra no sólo intentó alisar esas acritudes en el sentir criollo, dio un paso más como intendente de Caracas: trabó importantes alianzas, se ganó la confianza de los mantuanos ${ }^{1}$ más destacados y les garantizó su amistad en la metrópoli, dejando personas leales a él en la provincia venezolana que responderían en nombre de Saavedra por favor y protección, y él, desde la misma corte, daría protección a los hijos de la élite caraqueña que se aventuraran a cruzar el Atlántico español en busca de una carrera cortesana, política, comercial, educativa o militar.

Los personajes que se congregan alrededor del ilustrado sevillano tendrán algo en común: por un lado son todos hijos del mantuanaje caraqueño y encumbrarán -breve y tímidamente- en la corte bajo la venia del favor de Francisco de Saavedra; y por otro, habrá una correspondencia política de unos caraqueños en la corte con Saavedra y otra con funcionarios en Caracas colocados por el sevillano; estos dos grupos, en ambas playas atlánticas, los hemos denominado el Círculo de Saavedra.

Este trabajo aspira comprobar nuestra teoría de que la élite criolla caraqueña gozó de la protección y el favor de Francisco de Saavedra y a su vez, éstos fueron leales con quien fuera su intendente desde 1783 hasta 1788, esa conexión de lealtades y afectos generó un círculo de influencia y un lobby atlántico.

\section{La vertiginosa carrera de un ilustrado}

Uno de lo hombres de Estado más brillantes de la España moderna fue el sevillano Francisco de Saavedra² (Sevilla, 1746-1819). En los albores de su exito-

1. «Mantuano», término original de Caracas, de la primera mitad del siglo XVIII, derivado del «manto» y su uso exclusivo por las señoras de los grandes propietarios y nobles de la colonia.

2. HeRmosilla molina, Antonio, La enfermedad de un sevillano de la Ilustración: Francisco de Saavedra 1746-1819, Sevilla, Real Academia de Medicina de Sevilla, 1975; MOLINA MARTínEZ, Miguel «El fondo Saavedra del Archivo de los Jesuitas en Granada», Archivo Hispalense, $\mathrm{n}^{\circ}$ 207-208 (1985), pp. 375-377; MOORE TOPPING, Aline, The Journal of Don 
sa carrera se vinculó con figuras determinantes como Alejandro O'Reilly, el conde Fernán Núñez y los hermanos Gálvez ${ }^{3}$. Tempranamente fue un destacado militar (Argel, Cuba, Pensacola, Jamaica...) y brillante político-administrador (Secretaría Universal de Indias, comisionado regio en México, La Habana, intendente en Caracas). En octubre de 1782 fue nombrado intendente de Caracas. Esta investidura, más que un premio por su luminosa hoja de servicios hasta ese momento, fue posiblemente el hecho de que Saavedra era uno de los hombres con mayor capacidad para hacer frente en amplios sentidos (económicos, políticos, administrativos y militares) al estratégico territorio de Venezuela.

Marchaba entonces el primer intendente Ábalos, y asumía la intendencia el sevillano. A partir de esta experiencia venezolana de Saavedra (1783-1788), por lo demás provechosa, tanto para él como en alguna medida para la organización de la provincia ${ }^{4}$, fue cuando se tejieron las relaciones -futuras- de los caraqueños en la corte de Carlos IV.

La mirada de la provincia de Venezuela de este ilustrado es vital para comprender una realidad económica y social que perfilaba el futuro político de la región. Deja muy claro la injusta balanza entre cosecheros del cacao y sus comerciantes posteriores «De los frutos a excepción del cacao establecido desde lo antiguo, y que según los mejores cálculos, es el que menos ganancia rinde a sus cultivadores, los demás se hallan muy a los principios $»^{5}$. Saavedra

Francisco Saavedra de Sangronis 1780-1783, Gainsville, University of Florida Press, 1989; MOLINA MARTínEZ, Miguel, «Ilustración y reforma. La biblioteca del intendente Francisco de Saavedra», Chronica Nova, no 19 (1991), pp. 271-289. LÓPEZ CANTOS, Ángel, Francisco de Saavedra, Segundo Intendente de Caracas, Sevilla, Estudios Hispanoamericanos de Sevilla, 1973; MORENo Alonso, Manuel, Memorias inéditas de un ministro ilustrado, Sevilla, Editorial Castillejo, 1992; LASERNA GAITÁn, Antonio Ignacio, El Fondo Saavedra, Granada: 1995; LASERNA GAITÁN, A. I., «La esclavitud para Francisco de Saavedra. Una propuesta al Consejo de Indias para la abolición parcial de la trata en 1792», Revista del Centro de Estudios Históricos de Granada y su Reino, no 8 (1994), pp. 153-170; MORALES PADRÓn, Francisco, Diario de don Francisco de Saavedra, Sevilla, Universidad de SevillaCSIC, 2004; MALdONAdo VIloRIA, Zulimar, «La Provincia de Maracaibo a fines del siglo XVIII: la visión de Francisco de Saavedra y José Domingo Rus», Revista de Ciencias Sociales, vol. XIV, no 3 (2008), pp. 575-589.

3. LÓPEZ CANTOS, Ángel, Francisco de Saavedra..., p. 2.

4. García-Baquero plantea que en efecto hay una época de esplendor del comercio provincial, desde Saavedra hasta 1790; asimismo Juan Andreo García extiende esta racha de prosperidad hasta 1796 según la balanza comercial de lo que él ha denominado el «trienio preconsular». GARCÍA-BAQUERO GONZÁLEZ, Antonio, «El comercio de neutrales en Venezuela (1796-1802)», Boletín de la Academia Nacional de la Historia (BANH), nº 271 (1985), pp. 673-703 y ANDREO GARCÍA, Juan, «Del "Libre Comercio" a la quiebra del sistema colonial (1789-1796). El comercio exterior de Venezuela», Estudios Americanos, $n^{\circ} 2$ (1994), p. 25.

5. Correspondencia de Francisco de Saavedra a José de Gálvez, La Guaira 24 de octubre de 1783. Legajo 478. Archivo General de Indias, (AGI), Caracas. 
sugiere la injusticia del sistema monopólico de la Compañía Guipuzcoana. Con este análisis el intendente nos conduce a revisar aquella riqueza de los mantuanos que cultivaban el cacao, pues al parecer esa prosperidad se forjaba más por las vías del contrabando que del comercio monopólico, lo cual nos lleva a una obligada consideración historiográfica del manido tema del cacao y la Guipuzcoana en Venezuela, materia para otro estudio.

Describe a una región más bien pobre ${ }^{6}$ y que consume poco. Esta mirada de la provincia en este momento es crucial, pues nos saca del atolladero historiográfico de creer que los "grandes cacaos"7 eran muchas familias, prósperos y acaudalados clanes mantuanos desde siempre. Esta idea de provincia "pobre" nos conduce a comprender la fase siguiente del florecimiento de la agricultura y la agroexportación con la desaparición del monopolio de Real Compañía de Caracas, unido a cierto fortalecimiento de las instituciones como la intendencia y el consulado.

Una provincia "pobre" en la cual su élite llevó a cabo, sin mayor dificultad, una apertura étnico-estratégica ${ }^{8}$ con el personal vasco-navarro de la poderosa Compañía de Caracas, donde este asociacionismo fue celebrado en la medida que se diversificaban las estrategias familiares de expansión comercial (grandes haciendas poco explotadas por falta de inversión, aliadas con un sector agroexportador emergente y relacionado con la Real Hacienda) por lo que la vieja y benemérita clase mantuana abría sus prestigiosos e históricos nichos

6. AGI, Ibid.

7. Ángel Rosenblat dice de los grandes cacaos: «Entre los mantuanos ocupaban el primer lugar los pocos condes y marqueses criollos que habían comprado sus títulos con remesas de cacao (...)». Anota el filólogo que el uso de esta expresión sobrevivió en el acervo popular como «ser un gran cacao» o «echárselas de cacao». ROSENBLAT, Ángel, El español en América, Caracas, Biblioteca Ayacucho, 2002, p. 270. El mismo término se utiliza en la literatura sobre esta élite, y apunta Herrera Luque en su novela histórica Los Amos del Valle, que «gran cacao» era en Venezuela la forma despectiva de referirse a los títulos nobiliarios. HerRera luQue, Francisco, Los Amos del Valle, t. I, Caracas, Pomaire, 1979, p. 414.

8. Unido a esto, recuérdese que el funcionario vasco-navarro que emigraba era por lo general soltero (el 82\%) con una composición por edad entre los 15 y los 30 años. Esta coincidencia de factores permite la alianza estratégica de éstos con las familias mantuanas con hijas casaderas, en miras de una asociación que interesaba y prestigiaba a las dos partes y a un proyecto económico-familiar con todas las de ganar. Sobre los porcentajes y las tasas migratorias del siglo dieciocho ver MÁRQUEZ MACÍAS, Rosario, «La emigración española a América en la época de las Luces», en ESCUDERO, José Antonio (coord.), Españoles de ambas orillas. Emigración y concordia social, Madrid, Sociedad Estatal de Lisboa 98, 1998, pp. 41-56; véase también ANGUlO MORALES, Alberto y ÁlVAREZ GILA, Óscar (coords.), Las migraciones vascas en perspectiva histórica (siglos XVI-XX), VitoriaGasteiz, Universidad del País Vasco, 2002, pp. 93-111; GÁrATE OJANGUREN, María, «Navarros y guipuzcoanos unidos en empresas económicas del siglo XVIII», Revista Internacional de los Estudios Vascos, ${ }^{\circ} 1$ (1992), pp. 25-42. 
a una clase que a su vez cumplía con todos los requisitos en clave antigua (limpieza de sangre, hidalguía y solar), donde todos alcanzaron un entendimiento cordial con miras al crecimiento mutuo. Buena parte de este "entendimiento" fue propiciada por Saavedra al configurar junto con la élite criolla, las primeras nóminas del Real Consulado de Caracas.

Saavedra para fundar las bases de la recuperación económica en la provincia venezolana, según su formación y sus ideas ilustradas, se codeó con las personas que para él eran las más adecuadas. Hombres que le dieran toda clase de información útil, asistencia logística, apoyo político y ciertamente estimación. De aquí que subsistieran algunas relaciones de éstas una vez que varios de los hijos de las notables figuras que apoyaron a Saavedra, viajaran a la villa y corte con proyectos concretos en la metrópoli. Tres buenos ejemplos son Feliciano Palacios y Sojo ${ }^{9}$, Manuel de Clemente y Francia y Juan Vicente Bolívar -padre de Simón Bolívar-. Del viejo Bolívar podemos traer a colación un breve episodio. En una de las inspecciones de las cajas reales, en el pueblo de La Vitoria, Saavedra se enteró de que Juan Vicente Bolívar estaba agonizando, en consecuencia a esta noticia el intendente dio la orden de suspender la inspección y regresar a Caracas, lo que suponía un importante atraso para sus inspecciones en la provincia. Su preocupación por la salud de Juan Vicente Bolívar describe el grado de compenetración que buscaba alcanzar Saavedra con sus adeptos criollos.

\section{Un entusiasta de la élite criolla americana}

Saavedra desde muy temprano mostró interés por el desarrollo de la élite criolla americana, para estimular su adhesión al sistema imperial, así como para explotar sus potencialidades en el desarrollo de sus respectivas provincias. Un ejemplo de este entusiasmo es Arango y Parreño, criollo habanero que siendo muy joven se codearía con el sevillano en La Habana, durante las tertulias familiares donde Saavedra pudo ejercer alguna influencia en la formación de Arango. Saavedra en estas reuniones buscaba motivar a los hijos de la élite criolla sobre los beneficios y la importancia de viajar a la metrópoli para formarse y hacer carrera ${ }^{10}$. Así pues en 1787 el joven criollo ingresaba en la

9. Cuando arriba Esteban Palacios a Madrid, Saavedra está sirviendo en el Supremo Consejo de Guerra. Allí estará hasta el 7 de noviembre de 1797 para ser nombrado Ministro de Hacienda. En marzo de 1798, en una condición prácticamente interina fue nombrado secretario de Estado.

10. RISCO, Antonio, La Real Academia de Santa Bárbara de Madrid (1730-1808). Naissance et formation d'une elite dans l'Espagne du XVIIIème siècle, 2 vols., Toulousse, Universidad de Toulousse-Le Mirail, 1979; GONZÁlez-Ripoll, Ma Dolores, «Vínculos y redes de 
academia de jurisprudencia de Santa Bárbara de Madrid, prestigiosa casa de estudios, dirigida por uno de los hermanos Gálvez, Miguel. En la primavera de 1789, Arango y Parreño obtuvo el título de abogado ${ }^{11}$. Es también durante esta época su primera vivencia en la corte (1787-1794) cuando procederá como apoderado del ayuntamiento de La Habana ${ }^{12}$. Esta exitosa carrera cortesana fue gracias a su protector en las altas instancias del gobierno, pues Saavedra logró promover la formación de la Junta de Agricultura y la realización del viaje al extranjero que quería emprender el joven Arango y Parreño ${ }^{13}$.

Francisco de Saavedra pertenecía a una época y a una "corriente" de políticos cortesanos y consejeros ilustrados que entendían la importancia de América a la vez de su fragilidad política ${ }^{14}$. El 9 de marzo de 1786 Saavedra manda a publicar un bando que notificaba la apertura de cuarenta plazas para americanos en el Real Seminario de Nobles de Madrid"15. Esa "nueva sensibilidad" de Saavedra por América y por sus amigos -antiguos aliados en Caracasfue a tono con varios proyectos que se tenían en mente. Unos se realizaron otros se desestimaron, tal y como la creación del Colegio de Nobles Americanos en Granada (planteado durante el período de Floridablanca como ministro de Estado entre 1787 y 1792) o la Compañía Española de Caballeros Americanos de la Guardia de Corps, con mejor suerte, pues fue erigida al final de la etapa de Saavedra en el supremo consejo de guerra (de 1788 a noviembre de 1797$)^{16}$. Fue una época donde la percepción política hacia los territorios de ultramar iban desde el optimismo de unos como Floridablanca ${ }^{17}$, el pragmatismo de otros

poder entre Madrid y La Habana: Francisco Arango y Parreño (1765-1837), ideólogo y mediador», Revista de Indias, n $^{\circ} 222$ (2001), p. 302.

11. La autora consiguió las exposiciones hechas en la academia de Santa Bárbara de Madrid por Francisco Arango y Parreño: «Las causas justas de la guerra» y «El poder legislativo», expuestas el 30 de octubre de 1787 y el 19 de octubre de 1788 respectivamente. En «Catálogos de Disertaciones en la Academia de Santa Bárbara de Madrid (17561806)», Ibid., t. II, no 1130 y 1154. Las certificaciones de estudios y exámenes de Francisco Arango y Parreño en Consejos. Leg. 12148, nº 30. Archivo Histórico Nacional (AHN).

12. AMORES CARREDANO, Juan Bosco, «El joven Arango y Parreño: Origen del proyecto político-económico de la sacarocracia habanera (1786-1794)», Temas Americanistas, no 12 (1995), p. 25.

13. GONZÁLEZ-RIPOLL, Mª Dolores, «Vínculos...», p. 302.

14. NAVARRO GARCíA, Luis, «Fluctuaciones de la política colonial española de Carlos III a Isabel II», en Pizarro Gómez, Javier (ed.), De súbditos del Rey a ciudadanos de la Nación, Castelló de la Plana, Universidad Jaume I, 2000, p. 78.

15. HAMPE MARTíneZ, Teodoro, «La colección de Hans Heinrich Brüning: un inventario de los documentos coloniales relativos al Perú», Colonial Latin American historical review, vol. 7, no III (1998), pp. 293-333.

16. LóPez Cantos, Antonio, Francisco de Saavedra..., p. 4.

17. HERRERA GUILLÉN, Rafael, «La buena administración de América: Floridablanca y la transformación de la idea americana de los Austrias», Res publica, nº 21 (2009), pp. 169-176; 
como Gálvez ${ }^{18}$ (los dos abogaban por intensificar el comercio de la metrópoli con América hispánica) y el pesimismo de Aranda ${ }^{19}$ y Ábalos ${ }^{20}$-este último fue el primer intendente de Caracas- quienes tenían serias dudas sobre la adhesión de los criollos americanos a España. Aranda en particular, tras su período de embajador en París, entendió la amenaza del espíritu independentista que cundía en el Nuevo Mundo después del ensayo exitoso de las trece colonias norteamericanas.

Miembros de algunas de las más destacadas familias de la élite criolla caraqueña serán los leales colaboradores de Saavedra durante su intendencia: los Palacios-Blanco/ Bolívar, los Fernández de León -aunque de origen extremeño estaban radicados en Caracas desde largo tiempo-, los Mallo, los Montilla, los Iriarte, los Clemente y Francia, los Aristiguieta, los Bernal, entre otros. Como una suerte de mapa estas familias nos proporcionan las rutas y caminos de los criollos caraqueños en la metrópoli. Por un lado Saavedra aunado a los Mallo ${ }^{21}$, Los Palacios y Blanco y los Ibarra Galindo, y por otro el caraqueño marqués de Uztáriz $^{22}$ a los Rodríguez del Toro ${ }^{23}$. Ellos serán destacados miembros directos e indirectos del círculo saavedrano en los enrevesados laberintos de la corte.

HERNÁNDEZ FRANCO, Juan, La gestión política y el pensamiento reformista del conde de Floridablanca, Murcia, Universidad de Murcia, 1984, p. 173; HERNÁNDEZ SÁNCHEZBARBA, Mario, «El americanismo del Conde de Floridablanca», Anales de historia contemporánea, vol. 8, (1992), p. 51. Acota este último autor que cuando Floridablanca propuso por escrito su plan de gobierno, tras una década de ejercicio del poder, de 395 puntos de su programa, América suponía 65 ítems. El tercer lugar de prioridades entre seis grandes segmentos: materia eclesiástica, instituciones civiles, América, ejército, hacienda y política exterior.

18. PRIETSLEY, Herbert, José de Gálvez, visitor general of New Spain (1765-1771), Beckley, University of California, 1916; vÁZQUEZ DE ACUÑA, Isidoro, «El ministro de Indias Don José de Gálvez, Marqués de Sonora», en Revista de Indias, (1959), pp. 449-471; NAVARRO GARCía, Luis, Don José de Gálvez y la Comandancia general de las Provincias internas del Norte de Nueva España, Sevilla, CSIC, 1964; CLARET, Pompeyo, José de Gálvez, Marqués de Sonora, visitador general de la Nueva España y fundador de la California, ministro de Indias con Carlos III, Barcelona, Gráficas Casulleras, 1963; SOLANo, Francisco, «Reformismo y cultura intelectual. La biblioteca privada de José de Gálvez, ministro de Indias», Quinto Centenario, no 2 (1981), pp. 1-100.

19. vallejo GARCíA-HEVIA, José María, «El conde de Aranda y los reinos de las Indias», en El conde de Aranda y su tiempo, Zaragoza, Instituto Fernando el Católico, 2000, pp. 537-555.

20. LUCENA GIRALDO, Manuel, Premoniciones de la independencia de Iberoamérica las reflexiones de José de Ábalos y el conde de Aranda sobre la situación de la América española a finales del siglo XVIII, Madrid, Doce Calles, 2003.

21. BEERMAN, Eric, «La pintoresca vida del payanés Manuel Mayo», Boletín de Historia y Antigüedades, no 782-783 (1990), pp. 1090-1098; miramon, Alberto, Dos vidas no ejemplares: Pedro Fermín de Vargas y Manuel Mallo, Bogotá, Biblioteca Eduardo Santos, 1962.

22. EGEA LÓPEZ, Antonio, «El caraqueño Marqués de Uztáriz, Intendente de Córdoba y Asistente de Sevilla», Andalucía y América en el siglo XVIII. Actas de las IV Jornadas de Andalucía y América, Sevilla, (1985), pp. 203-232.

23. QUinTERo, Inés, El Último Marqués. Francisco Rodríguez Del Toro, 1761-1851, Caracas, Fundación Bigott, 2005. 


\section{El Círculo de Saavedra}

4.1 Breve galería de los personajes más relevantes del Círculo de Saavedra en ambas playas atlánticas

Feliciano Palacios y Sojo ${ }^{24}$, el mantuano patriarca de los Palacios y Blanco, abuelo de Simón Bolívar. Gracias a una epístola de Francisco de Saavedra dirigida a él, vimos por vez primera una relación del sevillano con los criollos caraqueños, que sobreviviría los años de la intendencia de Saavedra: "(...) le manifesté [a Esteban Palacios] mis deseos de obsequiarle y el gusto que tendría en contribuir al buen éxito de los negocios que le traen a esta hasta donde alcancen mis cortas facultades. Yo valgo poco pero este pequeño valimiento en nada lo emplearé tan gustoso como acreditar a Vm. y a estos señores el constante afecto que les profeso y la reconocida memoria que conservo a sus favores" 25 .

María Concepción Palacios, madre de Simón Bolívar, hermana de Esteban, Pedro y Carlos Palacios, nació en 1758 y murió en 1792. Viuda desde muy joven. El sabio Vicente Lecuna la cataloga como "de notables dotes sociales, reunía a su alrededor numerosas relaciones, con gracia tocaba el arpa". Fue una sagaz defensora de su fortuna, de sus privilegios y de su estatus. Fue patrocinadora de la primera etapa de la aventura cortesana de su hermano Esteban Palacios. Auspició todo el dinero con el fin de gestionar dos títulos nobiliarios para sus hijos Simón Bolívar y Juan Vicente Bolívar. Apoyó la carrera de guardia de corps de Esteban Palacios. Francisco de Saavedra la recuerda con mucha estima en una epístola dirigida al padre de ella: "(...) Sírvase Vm. ofrecer mis respetos a los pies de mi Señora Doña María de la Concepción (...)"26.

Esteban Palacios (1764-1830), será el cortesano de la familia PalaciosBlanco/Bolívar. Su carrera cortesana comienza a finales del dieciocho y termina

24. Esta fue una gran amistad de Saavedra en Caracas (1730-1792), era hermano de un hombre que gozaba de mucha confianza del intendente: Francisco Sojo (reconocible en la documentación como el "Dr. Sojo") quien ha generado una pequeña confusión en López Cantos y Demetrio Ramos Pérez cuando estudian la inspección de Saavedra a las cajas reales de Puerto Cabello, lo confunden con Feliciano Palacios y Sojo. La desambiguación de este influyente personaje fue posible a través de una queja que reposa en el Archivo General de Indias. Véase LóPEZ CANTOS, Ángel, Francisco de Saavedra..., pp. 51-52 y 95; RAMOS PÉREZ, Demetrio, «A los dos siglos del viaje a España de Simón Bolívar. La causa y su deseo de instalarse en la corte para algo muy distinto que la carrera de armas», Boletín de la Real Academia de la Historia, t. CXCVI, cuaderno I, (1999), p. 11; Caracas, 17-X-1774. Leg. 234, (AGI).

25. LECUNA, Vicente, «Adolescencia y juventud de Bolívar» [a partir de ahora citaremos Epistolario], Boletín de la Academia Nacional de la Historia (Venezuela), t. XIII, no 52 (1930), pp. 489-490.

26. Ibid. 
en las Cortes de Cádiz como diputado no reconocido por Caracas, denominado suplente ante la negativa de Venezuela de participar en la convocatoria gaditana. Buena parte de su vida transcurre en la metrópoli pues viaja a los 28 años de edad, pasando lejos del terruño 33 años continuos. Fue guardia de corps, más tarde gozó de un pequeño cargo como ministro de la contaduría real de hacienda. Su vida en corte fue determinada por la protección de Francisco de Saavedra y su amistad con Manuel Mallo, este último nacido en Popayán (Nueva Granada) y criado en Caracas. Esteban Palacios fue determinante para traer a España a su sobrino y ahijado Simón Bolívar, y será quien haga la logística de hospedaje, formación, educación y relaciones cortesanas. A través de Esteban Palacios, Bolívar conocerá al marqués de Uztáriz, el maestro más determinante en la formación del futuro Libertador venezolano. Palacios sufrió la caída en desgracia cortesana, fue preso y luego, al salir de su reclusión, vivió en Barcelona una larga temporada como director del Teatro Italiano. Regresó a Caracas en 1825 , recibido y protegido por su sobrino dilecto, ahora presidente de la Gran Colombia, Dictador del Perú, Libertador de Bolivia.

Pedro Palacios aprovechó la situación en corte de su hermano, viajó a la metrópoli el mismo año de Simón Bolívar, en 1799. Quiso beneficiarse con la posición de Esteban Palacios, de Manuel Mallo y la protección de Saavedra. Será el más realista de sus circunstancias en corte. Un reclamo que tenía Pedro Palacios contra su hermano Esteban -muy sugerente- es cuando duda de sus cualidades cortesanas por no aprovechar situaciones como haber viajado en coche desde París hasta Madrid con Mariano Luis de Urquijo, sin insinuarle ningún favor político ni mantener una correspondencia con el ministro vasco. Regresaría Pedro Palacios para morir tempranamente en 1811 en Caracas.

Carlos Palacios será el encargado en Caracas de las haciendas y de los asuntos de sus hermanos cortesanos, Pedro y Esteban. Será quien mantenga mayor flujo epistolar con sus hermanos criollos en Madrid. Recibirá un importante favor de Francisco de Saavedra tras una persecución política en Caracas, como se verá en este estudio.

Antonio Mallo, padre de Manuel Mallo, el guardia de corps y mayordomo de semana del Palacio Real, que tanto compartió con Esteban Palacios y Simón Bolívar, es un personaje clave para entender el círculo de Saavedra en ambas playas del Atlántico, pues Francisco de Saavedra empezó a trazar las líneas fundamentales de esta cartografía de mantuanos en la España-corte desde 1783 en Caracas, como segundo intendente de la provincia venezolana. El principio de esta alianza con los criollos caraqueños se remonta a la erección del real consulado de Caracas, cuando Saavedra como intendente le sugiere a José de 
Gálvez su nómina de imprescindibles ${ }^{27}$. En ella destacan Antonio Mallo, Juan Manuel de Iriarte (casado con María Begoña Aristiguieta y Blanco, como veremos, de las Aristiguieta radicadas en Cádiz) y Francisco Sojo (hermano del padre de Esteban Palacios) muy vinculado a la administración de Saavedra y a la Real Hacienda. Antonio Mallo fue tesorero general de ejército y real hacienda de la provincia de Caracas bajo las órdenes de Francisco de Saavedra. Esta relación subsistirá al paso de los años; una vez que Saavedra encumbra, demuestra que es amigo de sus amigos. Gozó Antonio Mallo cargos en la Real Hacienda en Caracas, en las reales cajas de Puerto Cabello y en la Casa de la Moneda de Nueva España. En alguna manera la carrera exitosa de Antonio Mallo en la burocracia imperial, describe el peso específico de su hijo Manuel en la corte imperial.

Manuel Mallo, natural de Popayán. Aún era un niño cuando su familia se trasladó a Caracas. En diciembre de 1788 con diecisiete años de edad cumplidos, ya estaba en Madrid como cadete del regimiento de infantería de la Corona. En 1793 se le concede la plaza fija en el batallón veterano de Caracas, reconociéndosele la antigüedad como cadete del regimiento de infantería de la Corona. No tenemos noticias documentales de nuestro payanés-caraqueño hasta la información que nos concede Eric Beerman, quien plantea que la reina María Luisa le otorga el valimiento el 12 de marzo de 1798 como mayordomo de semana convirtiéndose así "en el gentilhombre secreto, en ejercicio y servidumbre de la reina María Luisa" ${ }^{28}$. La buena nueva llega a los círculos de la élite de Caracas y es tomada con entusiasmo. Significaba la posibilidad de densificar la red de venezolanos en corte: ascensos, cargos, nombramientos y relaciones en la capital del imperio. Y todo posible a través del paisano Manuel Mallo y la antigua amistad de su padre con Saavedra: el núcleo y germen del círculo de Saavedra. Manuel Mallo empezaba a vincularse con la red del poder cortesano desde el 12 de marzo 1798: "Para Mayordomo de Semana de mi Real Casa nombro a Dn. Manuel Mallo de Quintana y Dn. Joaquín Melgarejo y Sauxin. Tendréislo entendido y dispondréis lo correspondiente a su cumplimiento"29. También obtuvo una pensión vitalicia de 650 pesos fuertes anuales y otra similar, en caso de fallecimiento, para sus cuatro hermanas ${ }^{30}$, gracias a Melchor

27. Caracas. Correspondencia de Francisco de Saavedra a José de Gálvez. Leg. Caracas, 478. (AGI)

28. BEERMAN, Eric, «La pintoresca vida del payanés Manuel Mayo», Boletín de Historia y Antigüedades, no 782-783 (1990), pp. 1089-1090; MIRAmón, Alberto, Dos vidas no ejemplares: Pedro Fermín de Vargas y Manuel Mallo, Bogotá, Biblioteca Eduardo Santos, 1962.

29. Aranjuez, 12-III-1798, Marqués de Santa Cruz. Caja 610, expte. 26. Archivo General de Palacio (AGP).

30. BEERMAN, Eric, «La pintoresca...», p. 1091. 
Gaspar de Jovellanos, a la sazón ministro de Gracia y Justicia. Cuando Francisco de Saavedra fue nombrado ministro de Estado (1798-1799) Mallo actuó como una suerte de valido de la reina, mudó su residencia a una casa contigua al Palacio Real, la primera -aunque temporal- residencia de Simón Bolívar en la villa y corte.

Gerónimo de Uztáriz, II marqués de Uztáriz, guió la primera formación intelectual -y verdadera- de Simón Bolívar en Madrid. Fue también una suerte de protector de éste cuando empiezan las primeras fracturas del círculo saavedrano en la corte. Aunque el sabio marqués sufre también esta arremetida cortesana, ocurre poco más tarde por lo que Bolívar y él logran compartir hasta 1801 -contando los viajes a Bilbao y Francia de Simón Bolívar, indicados y recomendados por el propio marqués- una fructífera relación de discípulo y maestro. A través del marqués es que Bolívar se relaciona con los Rodríguez del Toro madrileños, conoce a su futura esposa, viaja a Bilbao con ellos y pasa a Francia, donde seguramente es testigo de las celebraciones de la Paz de Amiens en 1802. Años más tarde, Bolívar en diferentes cartas y conversaciones con sus futuros -y primeros biógrafos- reconoció y agradeció su vivencia en la casa del marqués de Uztáriz, acaso las más importantes y casi únicas pasantías con un maestro que dejaría, en alguna medida, huella en el futuro estadista continental.

Pedro Rodríguez del Toro, primo de Teresa Rodríguez del Toro, futura esposa de Bolívar, es uno de los grandes referentes de la cartografía paralela de venezolanos en la metrópoli de esta época. Caraqueño también, hermano del marqués del Toro, teniente coronel dispenso de los Reales Ejércitos, Caballero de la Orden de Santiago, es un personaje clave para el desenvolvimiento de Bolívar en su primer viaje a Bilbao. Fue su apoderado en Santander para casarse por poderes, y en un repentino cambio de planes de Bolívar y Teresa Toro, es uno de los testigos del matrimonio Bolívar-Rodríguez del Toro en Madrid en 1802, donde declara que vivía para entonces en la calle Fuencarral número 2, la misma casa de su prima Teresa, prometida de Bolívar.

Manuel Felipe de Clemente y Francia, caballero de la orden de Santiago, natural de villa de Haro, un nuevo patricio caraqueño, estuvo vinculado con la Real Compañía Guipuzcoana de Caracas, miembro del Real Consulado de Caracas y de todo aquello que describía el quehacer de la elite en la provincia venezolana. Era propietario de una fragata (la San Carlos) que exportaba cacao a Veracruz. Su hijo Pablo Clemente Palacios y Francia (hermano de Lino Clemente) estaba casado con María Antonia Bolívar Palacios, hermana mayor de Simón Bolívar. 
Lino Clemente Palacios Francia Jerez Aristiguieta, (hijo de Manuel Felipe de Clemente y Francia) estaba en la metrópoli desde 1786 cuando sienta plaza de guardiamarina en la Armada Real. Dos años más tarde asciende a alférez de fragata, en 1792 a alférez de navío y tres años antes de que viniera su padre a la metrópoli, en 1793, ya era teniente de fragata. Este caraqueño, del pueblo de Petare, en 1800 obtuvo su retiro con la graduación de teniente de navío. Regresó a Venezuela. Se casó el mismo año en primeras nupcias con María del Carmen de Iriarte y Xerez de Aristiguieta y en segundas nupcias con su cuñada María Vicenta de Iriarte y Xerez de Aristiguieta. Lino Clemente realizó el camino brillante de un criollo en la metrópoli. Más contemporáneo con Esteban Palacios que con Simón Bolívar, era cuñado de Francisco José Bernal (radicado en Cádiz); por la obligación de la época y de las fechas, tuvo que rondar los ambientes gaditanos entre sus coterráneos, sus paisanos pares que en España proyectaban penetrar la corte, para formarse. Varios de ellos miembros del Círculo de Saavedra. En 1811 se involucró con el movimiento independentista venezolano, fue uno de los firmantes del Acta de Independencia, capitán de navío en 1812, comandante general de los cuerpos de artillería y marina, general de brigada del Ejército Libertador en 1814, envestido por el Congreso de Angostura como mayor general de la Marina Nacional en 1819. Es el primer ministro de defensa en la historia republicana venezolana.

Francisco José Bernal fue contador del Ejército, ministro de la Real Audiencia, secretario por comisión de la Capitanía General y compadre del gobernador-capitán general de Venezuela (1786-1792), el sevillano Juan Guillemi. La carrera de Francisco José Bernal comenzó a los 22 años de edad como oficial en las cajas reales de Santa Marta en 1771. Más tarde pasó a Riohacha, con el mismo cargo, hasta 1776 cuando finalmente llegó de la mano del virrey Manuel Flórez a Santa Fe, en el Nuevo Reino de Granada, como su "secretario de cartas (...) agregándole al mismo tiempo [Flórez] a la secretaria en clave de ministro sin sueldo alguno". En el año de 1784 Bernal logra un ascenso a oficial tercero. Mereció la estima y la confianza del virrey santafereño, pues fue comisionado para viajar a la corte con los papeles reservados pertenecientes a la sublevación de Santa $\mathrm{Fe}^{31}$. Esta misión mereció que le ascendieran el 23 de octubre de 1786 a contador de Ejército y ministro de la real hacienda del puerto de La Guaira. Bernal llegó a Venezuela en abril de 1787. Más tarde viajó a la España-corte, arribando a la península en 1791 por el puerto de

31. FELICE CARDOT, Carlos, Rebeliones, motines y movimientos de masas en el siglo XVIII venezolano (1730-1781), Caracas, Academia Nacional de la Historia, 1977; MARTínEZ SHAW, Carlos, «El despotismo ilustrado en España e Indias», en MíngUEz, Víctor y CHUST, Manuel (eds.), El imperio sublevado, Madrid, CSIC, 2004, p. 170. 
Pasajes, Guipuzcoa, en un bergantín de la Compañía de Filipinas ${ }^{32}$. Era una figura clave del Círculo de Saavedra entre Caracas y la metrópoli ${ }^{33}$. Su suegro, era Manuel Felipe de Clemente y Francia. Bernal fue también una suerte de administrador/procurador en corte de los Palacios Blanco, muy unido afectivamente con doña Concepción Palacios y Sojo, la madre de Simón Bolívar, hermana de Esteban, Carlos y Pedro Palacios. Será Bernal junto a Esteban quien se dedique a gestionar a finales del dieciocho en la Real Chancillería los títulos nobiliarios de conde de Casa Palacios y marqués de San Luis para los hermanos Bolívar (Simón, futuro Libertador y Juan Vicente respectivamente). Bernal, según la documentación explorada ${ }^{34}$, regresa de nuevo a España en 1796, junto con su suegro Manuel de Clemente y Francia. Estaba casado con Rafaela Clemente.

Mariano Montilla, a la sazón de la época que estudiamos, pertenecía a la guardia de corps (posteriormente será de los más importantes generales de Simón Bolívar en la guerra de independencia). Luchó en 1799 bajo las órdenes de Manuel Godoy en las hostilidades con Portugal, en el sitio de Olivenza.

Pedro Iriarte, Juan Iriarte, Pedro Martín Iriarte, son tres hermanos de origen vasco-navarro con casas comerciales en Caracas y La Guaira, más tarde en Cádiz. Se casaron, el mismo día los tres, con tres hermanas Aristiguieta, primas hermanas de la madre de Bolívar, Concepción Palacios y Blanco. Las hermanas Aristiguieta, muy sonadas a lo largo de finales del XVIII y buena parte del XIX, dejarán su huella en la sociedad mantuana caraqueña por sus extravagantes vidas. Una rama de las Aristiguieta se fue a España, donde encontramos a la

32. En 1793 Bernal regresa a Caracas, y retorna a la metrópoli en 1799. En esta ocasión fue secuestrado por los ingleses, y hecho prisionero en la isla Bermuda en compañía del recién nombrado obispo de Almería fray Juan Antonio de la Virgen María y Viana (obispo alavés que hasta esta fecha había sido prelado de Caracas). Tras 54 días de cautiverio consiguieron un bergantín en el que naufragaron. Felizmente salvaron la vida el obispo y Bernal. Secretaría de Despacho de Guerra, Archivo General de Simancas. Leg. 7175, 18. (AGS). Ver también LóPEZ, José Eliseo, La emigración desde la España peninsular a Venezuela en los siglos XVI, XVII y XVIII, vol. II, Caracas, Universidad Central de Venezuela, 1999, p. 388.

33. Francisco José Bernal solicita merced. Caracas, 1798. Secretaría de Estado y del Despacho de Estado (AGI). En una carta contenida en la documentación (la n ${ }^{\circ} 4$ del legajo) enviada por Pedro Carbonell -capitán general de Caracas- a Francisco de Saavedra, secretario de Estado y del Despacho Universal de Hacienda, remite la instancia de Francisco José Bernal, a la sazón secretario de la capitanía general, para solicitar una promoción a algún destino -España, México o La Habana- de la Real Hacienda. Esto demuestra cómo se teje una pequeña red en la anchura imperial con los finos hilos del Círculo de Saavedra.

34. Francisco Bernal, licencia a España. Leg. 7185, 7 (AGS). 
condesa de Río Molino ${ }^{35}$ y a las esposas de los hermanos Iriarte. El otro ramal se quedó en Caracas, enriqueciendo gran parte del anecdotario caraqueño del siglo XIX.

Esteban Fernández de León, intendente de la provincia de Venezuela (17931802), fue el miembro más destacado e importante del círculo de Saavedra en Caracas. Saavedra confió y delegó siempre en él, al punto de recomendarlo para que ejerciera la intendencia paralelamente con su cargo -de doce años hasta su nombramiento- al frente del «Ramo del Tabaco ${ }^{36}$. Bajo la protección de Saavedra, Esteban Fernández de León se enfrenta a influyentes sectores del comercio en la provincia ${ }^{37}$, representados en el real consulado de Caracas $^{38}$ por familias vasco-navarras ${ }^{39}$ (o vizcaínos en una acepción epocal), provenientes del poderoso lobby -herencia- de la Real Compañía Guipuzcoana de Caracas. Este personaje fue aliado de los "cosecheros", hacendados, mantuanos ligados a la producción agropecuaria más que al comercio. Asimismo, gracias al poder del Círculo de Saavedra en Caracas, Esteban Fernández de León logra enfrentarse exitosamente al gobernador y capitán general Pedro Carbonell en 1794 en una lucha de potestades entre la gobernación-capitanía general y la intendencia de cara a la guerra en el Caribe francés y el abastecimiento de tropas atracadas en Puerto Cabello. Fernández de León sale victorioso fortaleciendo definitivamente el peso específico de la intendencia. Su poder político y su amistad con los Palacios Blanco validan nuestra teoría de esta facción cisatlántica -el círculo saavedrano-inspirada por la impronta del sevillano durante su breve paso por Venezuela.

Ignacio Canivel (también escrito Canibell), es otro referente de peso de los mapas humanos de estos peregrinos cortesanos en su camino hacia la Españacorte, pues es uno de los personajes más destacados del círculo de Saavedra desde sus orígenes. Canibell fue amanuense de Saavedra desde el principio de su cargo de intendente caraqueño, en 1783. Embarca para Caracas desde Cádiz en febrero de $1783^{40}$ el mismo año que Saavedra se hace cargo de la intendencia

35. Protocolos Notariales de Cádiz, notaría de Alejandro de la Parra, 2266, 12-II-1811, fol. 103-108. Archivo Histórico Provincial de Cádiz (AHPC).

36. La aventura política de este personaje está plasmada en la obra ANDREO GARCíA, Juan, La Intendencia en Venezuela. Don Esteban Fernández de León Intendente de Caracas. 1791-1803, Murcia, Universidad de Murcia, 1991, pp. 70 y ss.

37. NUNES DIAS, Manuel, El Real Consulado de Caracas (1793-1810), Caracas, Academia Nacional de la Historia, 1971, p. 250.

38. Caracas, Esteban Fernández de León al Prior y Cónsul del Real Consulado acerca de expediente formado sobre que se arregle a precios fijos el aforo que se hace de los frutos para la exacción del derecho de Alcabala. 13-VIII-1796. Leg. Caracas, 917. (AGI).

39. Epistolario, pp. 531-532.

40. Casa de Contratación, 26-II-1783. Leg. 5526, n² 2, r. 6. (AGI). 
venezolana. Bajo el patrocinio de Saavedra fue ministro de la real hacienda en la isla de Trinidad ${ }^{41}$, y luego ministro contador del tribunal de cuentas de Caracas en la misma época "saavedrana". Más tarde fue ministro contador mayor del tribunal de cuentas de Caracas. Tuvo formación en Londres ${ }^{42}$, por lo que destaca en su hoja de servicio el manejo de otros idiomas. Cuando Saavedra hace viaje a la península en 1788, Canibell decide, en un gesto de lealtad, seguirle, no abandonar al sevillano. Al respecto le informa el gobernador de la provincia venezolana Juan Guillelmi a Antonio Valdés: “(...) Dn. Francisco de Saavedra, llevando consigo al secretario de dicha intendencia Dn. Ignacio Canibell que ha querido seguirle y no apartarse de su compañía. Particípolo a V.E. para su superior inteligencia y gobierno" ${ }^{33}$. En 1798 Canibell fue comisionado por Pedro Carbonell -entonces gobernador y capitán general de Venezuela- para cruzar el océano y llevar una documentación de grave importancia a las manos del rey. En el trayecto la corbeta mercante fue apresada ${ }^{44}$. En Lisboa se da cuenta de que el tablero político había cambiando en Madrid y comprende que la protección que había gozado hasta ese momento, se desvanecía con la partida de Saavedra.

Simón Bolívar, antes de volverse «El Libertador», viajó en 1799 con la finalidad de hacer una carrera cortesana, posiblemente vinculada a la diplomacia ${ }^{45}$. Alojado -al lado de la residencia de los monarcas- junto con sus tíos Esteban Palacios, Pedro Palacios y el guardia de corps -y para esa época mayordomo de semana del Palacio Real- Manuel Mallo, verá y sentirá el mundo cortesano de cerca. Su vivencia en Madrid fue placentera y provechosa hasta la caída en

41. Real orden de Antonio Valdés al intendente de Caracas, 25-IX-1787, caja 26, n 39, Archivo del Fondo Saavedra (AFS).

42. Anota Amunátegui que «Ignacio Canivell, caballero de buen sentido, que habiéndose educado en Londres, poseía el inglés y tenía una idea clara de los que era el Times y el gabinete británico» Amunátegui, Miguel Luis, Biografías de Americanos, Santiago de Chile, Imprenta Nacional, 1854, p. 42.

43. Intendencia de Caracas, 25-V-1788, no 8. leg. Caracas, 471, (AGI).

44. Según indica la carta: «Sin otra idea, ni objeto que el de cumplir lo prometido a V.E. en mi anterior representación fecha en Lisboa a 20 de septiembre último, tengo ahora el honor de pasar a sus manos en lugar del oficio del Presidente Gobernador y Capitán General de Caracas allí insinuado a V.E. una copia certificada por mi de la certificación original, que, antes de mi salida de aquel destino, me franqueó insertando su contenido cuyo documento dirigí a Norteamérica, para que en caso de extravío del oficio original, que rompí y eché al agua al tiempo de mi apresamiento, llegase por aquella vía con más seguridad a mis manos, como se ha verificado en comprobación de lo que en aquella fecha tengo dicho (...) Espero de la justificación de V.E. se digne mandárseme acuse de recibo de dicho documento. San Lorenzo el Real, 25 de diciembre de 1798». Estado, expte. de Ignacio Canibell, leg., 59, nº 13, (AGI).

45. RAMOS PÉREZ, Demetrio, «A los dos siglos del viaje a España de Simón Bolívar. La causa y su deseo de instalarse en la corte para algo muy distinto que la carrera de armas», Boletín de la Real Academia de la Historia, t. CXCVI (1999), pp. 9-41. 
desgracia de Francisco de Saavedra, y sucesivamente Manuel Mallo y Esteban Palacios. A partir de ese episodio político se refugiará en casa del caraqueño marqués de Uztáriz, a la sazón ministro del consejo de guerra en Madrid $^{46}$ (de 1795 a 1801). Ahí conocerá a su futura esposa Teresa Rodríguez del Toro, española hija del venezolano Bernardo Rodríguez del Toro y prima del paisano caraqueño también, Pedro Rodríguez del Toro, vinculado este último con los condes de Villares. En Bolívar convergen varios puntos de la cartografía humana de caraqueños en corte, tanto del círculo de Saavedra como una suerte de red paralela de venezolanos en los Rodríguez del Toro e indirectamente, los condes de Villares ${ }^{47}$. Uztáriz también caerá en desgracia en 1801, removido de su cargo y de la corte, es enviado a una comisión de segundo orden en Teruel ${ }^{48}$. Simón Bolívar se casará en Madrid en 1802, para regresar a su Caracas natal en vista de las circunstancias adversas que agobian a los miembros más cercanos del círculo de Saavedra en España, sus tíos Palacios y Manuel Mallo.

\section{El germen del Círculo}

Francisco de Saavedra empezó a trazar las líneas fundamentales de esta cartografía de mantuanos en la España-corte desde 1783 en Caracas. Un principio de este paisaje de gentes (o mapas humanos ${ }^{49}$ ) se remonta a la erección del

46. CARDozo uZCÁtegui, Alejandro, «Don Gerónimo Enrique de Uztáriz y Tovar. II Marqués de Uztáriz. Protector y maestro de Simón Bolívar en Madrid», Presente y Pasado, Mérida (Venezuela), no 31 (2011), p. 18.

47. El título de conde de Villares es concedido en 1792 a Martín de Avendaño y Cáceres, maestrante de la Real de Granada, vecino de Nueva Valencia del Rey en la provincia de Venezuela. El título de marqués del Toro lo ostentaría más tarde el hermano menor de Pedro Rodríguez del Toro, Francisco, quien sería el III marqués del Toro y general del Ejército Libertador desde 1811. Este título había sido concedido en 1732 a Bernardo Rodríguez de Toro, y su hijo, el II marqués del Toro, a la sazón, era hermano del padre de la prometida de Bolívar. Archivo Histórico Nacional, sección nobleza, Archivo de los Condes de los Villares. El nieto de Pedro (primo de la futura esposa de Bolívar y el anfitrión de Bolívar en Bilbao), llamado Pedro Enrique Rodríguez del Toro sería senador por la provincia de Segovia en la legislatura de 1879-1880, así también otro descendiente suyo, Pedro Rodríguez del Toro y Mesa, por la misma provincia, durante la legislatura de 1918-1919. HIS-0521-02, HIS-0521-02. (AHN).

48. CARDOZo uZCÁTEGUI, Alejandro, Simón Bolívar y Bilbao. El hombre antes del héroe, VitoriaGasteiz, Nuevos Aires, 2011, p. 120.

49. Los mapas humanos es nuestra forma de presentar aquella 'superestructura' de referentes, contactos, relaciones, influencias, amistades, conocidos y familia que describe el contexto vital de un sujeto frente al resto. Miguel Delibes escribió en Por esos mundos que «(...) en realidad, el mundo es un gigantesco puzzle y uno, a medida que viaja, va encontrando los fragmentos que precisa para componer un mapa humano coordinado y armonioso». garCía domínguez, Ramón, "El mundo y yo (Libros de viajes de Miguel Delibes)", en JIMÉNEZ LozAndo, José (coord.), El autor y su obra, Miguel Delibes, Madrid, Universidad Complutense, 1993, p. 173. 
real consulado caraqueño, cuando entonces como intendente, Saavedra le sugiere a José de Gálvez su nómina de imprescindibles ${ }^{50}$. En ella destacan Antonio Mallo, el padre de Manuel Mallo, Juan Manuel de Iriarte (casado con María Begoña Aristiguieta y Blanco, una alianza familiar esencial del círculo saavedrano de Cádiz) y Francisco Sojo (hermano del padre de Esteban Palacios a quien abordaremos seguidamente). Francisco Sojo como acotamos, estaba muy vinculado a la administración de Saavedra y a la real hacienda ${ }^{51}$.

Esta "nómina de imprescindibles" para emprender el proyecto del consulado caraqueño, es una configuración que diseña Saavedra según sus aliados mantuanos durante su intendencia. Se teje a partir de ese evento -crucial para el devenir de la política caraqueña- una relación quid pro quo en tanto él los halagaba y encumbraba en sus espacios políticos/comerciales naturales (Caracas, La Guaira, Puerto Cabello...) con los mejores cargos en el futuro consulado. Ese gesto correspondía al agradecimiento del sevillano por la amistad que estos mantuanos le profirieron durante su administración. Asimismo había garantías -como veremos- de que la estela saavedrana en Caracas subsistiría posteriormente a la partida del bienquisto intendente, es decir, el círculo de sus afectos que permanecería rigiendo los destinos de la provincia hasta los albores del siglo XIX, bajo una sombra que se proyectaba desde la misma corte, claro está, mientras Saavedra gozara las mieles del poder.

Esta situación quid pro quo tenía una fase siguiente y, acaso, sólo en sintonía con los más allegados personajes del Círculo de Saavedra como el hijo de Feliciano Palacios Sojo, Esteban Palacios. Vale recrearnos brevemente en algunos detalles de la larga aventura cortesana de este paradigmático criollo caraqueño, dilecto saavedrano. Palacios en la corte gozaba de la ayuda económica de su hermana Concepción. Esta mantuana había sido también promotora de la idea de que Esteban ingresara en la guardia de corps como forma de garantizar un futuro, prestigio y tener influencias en el "Palacio" "para con más facilidad evacuar los asuntos que traigo" ${ }^{52}$. Un mecanismo de agilizar los engorrosos, costosos y complicados trámites de la burocracia imperial.

Basados en la posición de poder/favorecedor de Saavedra y Mallo dentro de un efecto de cascada podemos entender el efecto del Círculo en la villa y corte. Saavedra apoya a un grupo de caraqueños que está más o menos al nivel de Mallo y Esteban, a su vez éstos auxilian a otros paisanos menos "conectados" que recurren a ellos para comprender el mapa de la villa y corte; pero algunas

50. Correspondencia de Francisco de Saavedra a José de Gálvez. Leg. Caracas, 478. (AGI).

51. Véase nuestra galería de personajes en el epígrafe 4.1.

52. LECUNA, Vicente, "Adolescencia y juventud de Bolívar", BANHV, t. XIII, (1930), n 52, p. 489. A partir de esta nota lo citaremos como Epistolario. 
palabras en el epistolario de los Palacios Blanco nos lleva a pensar que son dos fuentes de influencia aparte pero en un mismo círculo: Mallo heredero del poder y las amistades de su padre, a la vez favorecido por su carrera en la guardia de corps, asiste a su amigo y paisano Esteban (y su pequeñísimo ámbito: Pedro Palacios y Simón Bolívar) y al mismo tiempo Esteban tiene una amistad -o influencia- heredada de su padre Feliciano, que sí que había trabado una previa devoción -mutua- con el sevillano, quien agradecido y fraterno espera en la metrópoli con deferencia y consideración, a los descendientes del viejo patriarca Palacios Sojo.

Es decir, Esteban Palacios gozaba de dos líneas del Círculo, una heredada de su padre, otra, devenida de la dinámica del paisanaje a través de Manuel Mallo, quien al mismo tiempo es otro aventajado del Círculo, so herencia de su padre Antonio Mallo, igual que Esteban. En otras palabras, el Círculo saavedrano puede definirse como el favor que la prole de los grandes criollos y mantuanos de Caracas hereda de sus mayores, antiguos cofrades del sevillano ilustrado.

La estancia caraqueña de Saavedra fue apenas de cinco años, sin embargo logró generar un ámbito de poder sumamente interesante. Su regreso a Madrid -aunque con cierta ilusión de parte de los criollos en su retorno- fue precedido de la noticia de la muerte de su preceptor José de Gálvez. Se enteró de su muerte por medio de una carta desde México de la condesa de Gálvez, viuda del sobrino de aquél, Bernardo. Escribe el intendente el 7 de octubre de 1787, su sensación de incertidumbre al respecto: "Con la muerte del Sr. Ministro Gálvez no sé si se retardará o apresurará mi ida a España, y tampoco sé en qué me emplearán para allá" 53 .

Según el epistolario que se rescata en estas lícitas memorias "reconstruidas", vemos un itinerario, casi a los dos años siguientes, donde Saavedra está escribiendo desde Madrid y habla que se ha casado con Rafaela Yurreguiondo, camarista de la reina. Fechada en Madrid el 25 de enero de 1789. El 22 de julio del mismo año a Saavedra le ha sido dada por el rey una plaza en Supremo Consejo de Guerra, lugar de trabajo "libre de angustias y trapisondas de

53. Moreno Alonso propone una alternativa que intenta interpretar la vida de Saavedra en sus Memorias inéditas de un ministro ilustrado, un trabajo en el formato de memorias del sevillano, a sabiendas que él no sistematizó de esa forma sus Decenios ni otro documento de su archivo. Esta obra, advierte en la introducción Manuel Moreno Alonso, es una compilación de los Decenios, de sus cartas y de su archivo, reconstruido en un todo con ciertas modificaciones para darle hilo narrativo a modo de memorias divididas en once cuadernos. Aunque no son en efecto unas memorias propiamente, la estructuración a lo largo de los cuadernos se ciñe a la documentación del ministro. MORENo Alonso, Manuel, Memorias inéditas de un ministro ilustrado, Sevilla, Editorial Castillejo, 1992, p. 193. 
mando, por consiguiente es muy acomodado a mi carácter pacífico y amante de la libertad" ${ }^{\prime 4}$.

\subsection{Casuística del Círculo de Saavedra en Caracas}

Demostración de una alianza a través de una complicidad: los Xerez-Aristiguieta, los Iriarte y Francisco de Saavedra

Un pleito en la Caracas de Saavedra, de índole doméstico pero que logra llegar al ámbito de la política en 1787 , nos dibuja lo que podríamos denominar un fenómeno temprano de la dinámica del círculo saavedrano. Las hijas de la viuda de Miguel Aristiguieta, Josefa María Blanco y Herrera, encarnizaron un enfrentamiento con sus cuñados Iriarte (Pedro, Juan y Pedro Martín Iriarte) y sus medios hermanos del primer matrimonio de Miguel Aristiguieta (Martín y Nicolás Xerez Aristiguieta) por el tema del patrimonio familiar Xerez Aristiguieta. Estas hijas eran producto de las segundas nupcias del finado Miguel Xerez Aristiguieta. Los hermanos Iriarte junto a los hermanos Xerez Aristiguieta, deseaban tomar las riendas y recuperar la casa del padre difunto, en detrimento de su segunda familia. A la sazón, la viuda Josefa María, buscó refugio afectivo en el licenciado Juan José Mora, lo que abrasó más la situación, pues las hijas vieron en este personaje un protector mientras que los Xerez Aristiguieta y los Iriarte, consideraron una amenaza dentro de la familia que ellos deseaban controlar. De cualquier forma, en medio de la querella aparece el nombre de Francisco de Saavedra como protector de los hermanos Iriarte "(...) el Intendente de esta Provincia Don Francisco de Saavedra, favorecedor declarado de aquellos [Iriarte], por la estrecha amistad, que tiene con una de sus mujeres, y en cuya casa pasa las noches del año desde las Oraciones hasta las diez (...) Los Iriartes, nuestros Cuñados, esforzados en conseguir sus ideas, y bien puestos en lo mucho que les sirve el Intendente Don Francisco de Saavedra para todas sus ocurrencias"

Una hija de Josefa María Blanco y Herrera "solía recibir en su casa y a altas horas de la noche al intendente Francisco de Saavedra, a sabiendas del vecindario y pese a la reprobación manifestada por su propia madre" ${ }^{56}$. Al observar la protección y el apoyo especial que tuvo Saavedra con el criollo habanero Arango y Parreño, la honda intimidad que teje con los mantuanos en Caracas

54. Ibid., pp. 194-195.

55. 13-XI-1787. Leg. Caracas, 412. (AGI). Las cursivas son nuestras.

56. LANGUE, Frédérique, «Revoltosos aunque caballeros. Los umbrales del honor en la Caracas del siglo XVIII», en Fronteras y sensibilidades en las Américas, Madrid, Doce Calles, 2011, pp. $77-78$. 
-como acabamos de leer- unido todo el conjunto a una carta posterior del sevillano donde se pone a las órdenes del patriarca mantuano Palacios y Sojo, demuestra que este funcionario ilustrado forjaba gran empatía con los criollos del lugar donde desempeñaba sus funciones de gobierno. En Caracas más que en La Habana esta identificación mental y afectiva entre Saavedra y los criollos se acentúa. Ese, digamos afecto, era resultado del punto de vista "saavedrano" del mundo criollo americano el cual queda bastante claro cuando anota en México (1781) que esa amistad con los criollos era realmente "vínculos muy sagrados", los cuales debían ser procurados por la metrópoli. Una forma era "atrayendo a los hijos de los americanos ricos con empleos y distinciones que gocen en España, ya promoviendo matrimonios y enlaces de una parte a otra". Para que así se borre "el desprecio con que los europeos miran a los americanos y la antipatía y rencor con que estos, como es natural, les corresponden" ${ }^{\prime 7}$.

\subsection{Casuística del Círculo de Saavedra en Madrid}

\section{El mantuano cortesano: Esteban Palacios, Manuel Mallo y Francisco de Saavedra}

Esteban Palacios contaba con sus haciendas de cacao en los valles centrales de la provincia, sin embargo, en corte valía poco el prestigio de "señor del cacao" y el fruto de la producción de sus tierras siempre se vio amenazado por la guerra marítima. Valía más el auspicio -bajo palabra de una buena garantía- que era su hermana, Concepción Palacios, quien para la época que Palacios emprende la carrera cortesana (1792) era la viuda de uno de los hombres más ricos, poderosos e influyentes de toda la provincia, Juan Vicente Bolívar -padre de Simón Bolívar-. Los Iriarte, por ejemplo, sabían quién era Juan Vicente Bolívar, y por ende estaban enterados de que su viuda ${ }^{58}$ era hermana de Esteban Palacios. Esa circunstancia le supuso a Palacios, ya instalado en corte, algunos créditos y favores de parte de estos navarros. Desafortunadamente Concepción muere al poco tiempo del viaje de su hermano cortesano.

Esteban Palacios apenas llega a Madrid el 13 de julio de 1792, activa su más importante coordenada en el mapa humano de referentes: Saavedra, su primera

57. Cit. por morales padrón, Francisco, «México y la independencia de Hispanoamérica en 1781 según un comisionado regio: Francisco de Saavedra», Revista de Indias, $\mathrm{n}^{\circ}$ 115-118, (1969), pp. 335-358. Ver también GUTIÉRREZ ESCUDERO, Antonio, «Predicciones sobre la independencia de Hispanoamérica: textos para la reflexión en vísperas de un bicentenario», Araucaria, año 6, no 12 (2004), pp. 197-208.

58. Llama la atención que en La Guaira en 1788, dos años después de la muerte de Juan Vicente Bolívar, se estableciera la casa comercial La Viuda de Bolívar, aunque no rastreamos indicios de que hubiera alguna conexión con Concepción Palacios. Leg. Caracas, 939. (AGI). 
garantía cortesana. El antiguo intendente de Venezuela representa un eje nodal en este ensayo palatino de Esteban Palacios. Al respecto léase la carta del 25 de julio de 1792 escrita por Saavedra a su viejo amigo de Caracas, Feliciano Palacios y Sojo. Sin desperdicio alguno:

"Muy señor mío y mi estimado amigo: Llegó a esta felizmente el señor Don Esteban, y me entregó su apreciable de Vm. que recibí con la mayor satisfacción: al mismo tiempo le manifesté mis deseos de obsequiarle y el gusto que tendría en contribuir al buen éxito de los negocios que le traen a esta hasta donde alcancen mis cortas facultades. Yo valgo poco pero este pequeño valimiento en nada lo emplearé tan gustoso como acreditar a Vm. y a estos señores el constante afecto que les profeso y la reconocida memoria que conservo a sus favores.

Sírvase Vm. ofrecer mis respetos a los pies de mi Señora Doña María de la Concepción y demás señoras, reciba muchas expresiones de Rafaela, que estima como debe su atención y mándeme cuando guste interin ruego a Dios me gue. su vida muchos años.

B.L.M. de Vm. su más afectísimo servidor y amigo

Francisco de Saavedra" ${ }^{\prime \prime}$.

Se lee con claridad una deferencia hacia Concepción Palacios, varias palabras que denotan la vieja amistad, una consideración de su peso específico en las actuales circunstancias políticas y sobre todo la disposición de relacionar al recién llegado Esteban Palacios "y a estos señores". Todo esto indica que en 1792 las cosas no parecían muy complicadas gracias a este amparo cercano, casi de índole familiar. Además Palacios estaba claro en sus pretensiones y se encomendaba a los mapas humanos que traía consigo: "Llegué a Madrid el día 13 de éste y hasta ahora sólo he visitado a algunos señores a quienes vine recomendado, para irles formando el ánimo, para el mejor éxito de mis pretensiones" 60 .

Saavedra y Palacios escriben por casualidad -y por separado- el mismo día a Feliciano Palacios Sojo, lo cual indica la deferencia del sevillano en apresurarse en darle noticias a su viejo amigo allende el mar sobre el arribo de su hijo, ilusionado en las mieles de la corte. Esteban Palacios cuenta sobre su llegada a Madrid y asegura que no desea perder tiempo ni oportunidades según le dicta su agenda en la villa y corte. Las diligencias comprenden gestionar para sus sobrinos sendos títulos nobiliarios (marqués de San Luis y conde Casa Palacios), uno de los encargos más comunes de los criollos en la metrópoli.

Una vez que los mantuanos empiezan a gestionar este tipo de tramites se conectan con agentes del tejido de red receptivo, quienes por lo regular son

59. Epistolario, pp. 489-490.

60. Ibid., p. 494. 
expertos en temas similares, conocen bien los intríngulis de la Real Chancillería de Valladolid, asimismo observan quién puede ser un buen ancla en la corte. Igual ocurre con los títulos militares. Esteban Palacios es también el agente cortesano para sus hermanos y mayores, pues utiliza sus conexiones para buscar el nombramiento de "alférez real" ${ }^{16}$ de su padre.

Manuel Mallo forma parte de los más importantes aliados del círculo de Saavedra. Forjó una amistad perdurable con Esteban Palacios y lo animó a ingresar en la guardia de corps. Esta circunstancia hizo posible que en 1799 Simón Bolívar -quinceañero- hiciera las Españas, periplo paradigmático entre 1799 y 1801 que termina de certificar la hipótesis acerca de la protección y el favor de Saavedra con la élite caraqueña. Para comprender a Manuel Mallo es necesario entender a su padre Antonio Mallo y su relación con Saavedra, con la corte virreinal novohispana y con Madrid, de esta manera lograremos deducir el poder de los Mallo que en alguna medida se transferirá en los mantuanos que viajan a España.

Situémonos nuevamente en la época de la intendencia de Francisco de Saavedra en Caracas (1783-1788). La correspondencia de Saavedra con José de Gálvez abarca toda clase de información, reportes y pormenores. Desde los movimientos, la mecánica de la administración provincial y el orden social, hasta detalles donde no logra terminarse de divorciar lo político de lo íntimo. $\mathrm{Al}$ respecto de Antonio Mallo:

"Muy Señor mío. El día 21 del corriente, llegó al puerto de La Guaira en el bergantín de Cartagena, que condujo el correo Don Antonio Mallo, Administrador General de Rentas Reales de esta Provincia quien después de haber descansado algunos días en aquel pueblo, vino el 24 a esta ciudad, y se fue inmediatamente a vivir con su mujer, con la que se ha reconciliado, y queda haciendo vida maridable con olvido de todo lo pasado. Particípole a V.E. para su noticia"62.

Esto sugiere que a Gálvez le interesaban los pormenores de la dinámica provinciana, incluso temas del hogar a puerta cerrada. Penosamente no se ha podido rastrear de quién o qué se trataba "todo lo pasado", pero no podemos interpretar gracias a otros aportes como el que citamos enseguida al pie de página, que su vida «maridable» era inestable y además los adeptos de Mallo se lo tomaban

61. «Señor: el día 13 de este mes llegué a Madrid y en el mismo día me vi con Sáenz quien me dijo estaba despachando el título de alférez Real de Su Md. lisa y llanamente y con los mimos privilegios de la cédula de su concesión me ha asegurado que va en este correo, me alegro infinito por la satisfacción que resulta a Su Md. y por lo burlado que queden los émulos. Este me ofreció pasarme una copia del auto del Consejo la que no ha podido conseguir todavía aunque he mandado por ella, por sus muchas ocupaciones». Epistolario, p. 490.

62. Duplicados reservados del intendente de Caracas, Caracas 28-VI-1784. Leg. Caracas, 479. (AGI). 
como casi una cuestión de Estado. Frédérique Langue aporta un documento muy llamativo que deja en evidencia el comportamiento escandaloso de Antonio Mallo en la Caracas de finales del XVIII ${ }^{63}$. El análisis de este sujeto a través de Saavedra y Gálvez, es muy válido en cuanto permite calibrar con mayor exactitud a su hijo Manuel Mallo. En acercamientos biográficos ${ }^{64}$ anteriores de los Mallo se ha sugerido la idea de que fue el hijo quien ubicó en la administración real al padre, es decir, que Manuel una vez cercano a la reina María Luisa, aprovechó su estado de "favorito temporal" para colocar a todo su entorno familiar y de paisanaje. Sin embargo fue Antonio quien ya gozaba de un peso real dentro de las fuerzas políticas del momento y quien con su influencia determina decisiones importantes dentro de la maquinaria colonial. Por lo demás es bastante común que en la documentación de Saavedra pueda apreciarse el trato más que deferente hacia Antonio Mallo ${ }^{65}$.

Un buen ejemplo de ese trato especial hacia Antonio Mallo fue cuando visto implicado en un presunto defalco de las cajas reales en Venezuela, evento que lo alejó del poder, Saavedra expone un largo informe para explicar en qué circunstancias ocurrió esta irregularidad. El intendente argumenta desde las situaciones íntimas de Antonio Mallo ("desazones domésticas... disgustos y desavenencias que tuvo con su mujer") hasta temas en el plano profesional: "sirvió al Rey con todo el celo, eficacia y desinterés que es imaginable, que ha sido y es continua su asistencia a la oficina, laborioso y de un tesón y constancia infatigable en el trabajo". Para volver a insistir en el plano personal, afectivo e íntimo: "Su hombría de bien, su juicio y arreglada conducta es notoria; y lo mismo la moderación de sus gastos, los de su casa y dilatada familia de mujer y seis hijos que no pasan de los de una moderada decencia" ${ }^{\prime 6}$.

63. «Por cuanto en la noche del día treinta del próximo pasado mes, como a las once y media, estando recogidos en nuestra recámara, reclinados en nuestra cama, y al mismo tiempo desvelados e insomnes (...) oímos los pasos acelerados y golpes violentos e impetuosos con que tocaron a las puertas de nuestro palacio (...) en solicitud de nuestra persona para avisarnos de parte de la mujer de don Antonio Mallo, Administrados de la Real Hacienda, la cual con un hijo suyo pequeño habían salido al balcón de su casa, dando voces y clamores a los vecinos, para que noticiasen al Prelado Diocesano, que la favoreciese, porque estaba en próximo evidente peligro a perder la vida por los golpes y malos tratamientos que estaba recibiendo de su marido, y que todo el vecindario estaba escandalizado con el alboroto de gritos, voces y clamores que se oían de la referida mujer de don Antonio Mallo, de sus hijos, criados y criadas». LANGUE, Frédérique, «Revoltosos...», p. 81.

64. Véase MIRAMÓn, Alberto, Dos vidas no ejemplares... y BEERMAn, Eric, "La pintoresca vida...", pp. 1090-1098.

65. Duplicados reservados del intendente de Caracas, Caracas 31-III-1784. Leg. Caracas, 479. (AGI).

66. Duplicados reservados del intendente de Caracas, Caracas 30-VII-1785. Leg. Caracas, 479. (AGI). 
El documento continúa con una larga descripción del caso, con alegaciones que la mayoría de las veces son a favor de Mallo. Está claro que había una amistad importante entre Francisco de Saavedra y Antonio Mallo. El intendente procedió de una forma leal y solidaria con el atormentado Mallo rogando al monarca "perdonar al citado Ministro el descubierto en que se halla dignándose resolver al propio tiempo su colocación en España en empleo proporcionando a su mérito y circunstancias" 67 .

Antonio Mallo regresó a su puesto en la administración general de las rentas de la provincia de Venezuela por órdenes expresas de Su Majestad, se le devolvió toda envestidura de su cargo así como la entrega formal -con su peso simbólico- de "libros, papeles, caudales y demás que le pertenecía con arreglo en todo lo mandado por S.M." ${ }^{68}$. Antonio Mallo para esta época que analizamos era un personaje con peso específico tanto en la provincia venezolana, en la corte virreinal de Nueva España, así como en la villa y corte. Era pues una pieza principal del círculo de Saavedra que se engranaba en varias partes del imperio, demostrando además cuán articulada estaba la maquinaria colonial. No olvidemos que fue restituido por el rey gracias a la intervención de Saavedra. Asimismo, había sido reemplazado en tiempos del primer intendente Ábalos y luego restituido por órdenes de Gálvez "por motivo de haberse ausentado de esta Provincia" que no era otra cosa que la recomendación del intendente sevillano, como se ha constatado en la carta de julio de 1785 .

Antonio Mallo después de su larga -y extravagante- estancia en Caracas pasó a la corte virreinal en $1799^{69}$ en la superintendencia de la Casa de Moneda de México, como comisario ordenador. Con "honores de ministro de capa y espada del consejo de real hacienda", percibiendo un sueldo de sesenta mil reales de vellón "y la gracia de que se le abonen por la tesorería general las pensiones que disfrutan sus hijos en América"70 deja un rastro visible por la corte virreinal novohispana.

Decíamos líneas arriba que debíamos comprender a Antonio Mallo para entender el poder o la influencia de su hijo Manuel Mallo y de esta forma juzgar la carrera cortesana de su más cercano amigo y paisano en Madrid, Esteban Palacios y su familia (un hermano y un sobrino). Este mantuano Palacios activó una relación que fue cardinal en su devenir cortesano. Por carta de

67. Ibid.

68. Correspondencia de Francisco de Saavedra con José de Gálvez, 6-X-1784. Leg. 478. (AGI).

69. Llega por Veracruz a bordo del bergantín Tártaro con el empleo de superintendente de la Casa de la Moneda de Nueva España. 18-XII-1799, Instituciones Coloniales, Gobierno Virreinal, Correspondencia de autoridades, vol. 57, expte. 120. Archivo General de la Nación, México (AGN-M).

70. Archivo General de la Nación-México, expte. 41, vol. 174, 20-IX-1799, Instituciones Coloniales, Gobierno Virreinal, Reales Cédulas Originales y Duplicados. 
Palacios sabemos que ya ha adquirido una posición para traerse a su sobrino ${ }^{71}$. Esa coyuntura favorable fue en buena medida gracias a Mallo.

Manuel Mallo viaja a España "para su educación, luego que tuvo la edad correspondiente, eligió con su aprobación la gloriosa carrera de las Armas, entrando a servir de Cadete en el Regimiento de Infantería de la Corona, desde el $1^{\circ}$ de Noviembre del año 1789 hasta el 20 de dicho mes del próximo pasado de 91 , en que se le apuntó la Plaza y dio su licencia absoluta"72. Según seguimos explorando su expediente profesional y de vida, va apareciendo un personaje interesante, el marqués de Zayas ${ }^{73}$, como una suerte de favorecedor, probablemente una amistad heredada de su padre Antonio Mallo. Este marqués lo recomienda al rey en varias súplicas, hasta que en febrero de 1793 el monarca le concede la plaza de cadete del batallón veterano de Caracas, siendo Manuel cadete del regimiento de infantería de la corona ${ }^{74}$. A pesar de ese logro en su carrera militar, sabemos que su fortuna fue por distintos derroteros.

Cuando Manuel Mallo cumplía los 14 años de edad, Antonio Mallo fue ascendido a tesorero general de ejército y real hacienda de la provincia de Caracas bajo las órdenes de Saavedra. Hemos anotado los cargos que gozó Antonio Mallo en la real hacienda en Caracas, en las reales cajas de Puerto Cabello y en la casa de la moneda mexicana. De cierta manera la vida exitosa de su padre en la burocracia imperial se reflejaba en su hijo en la corte. Se le estimaba y respetaba a Antonio Mallo al punto que, como vimos, las autoridades le eximen de un asunto relacionado con la malversación de los fondos de la real hacienda de Caracas (o en todo caso sale airoso de un peligroso malentendido) y en el entorno de los funcionarios del rey se ordena que se le restituya el cargo con sus privilegios.

A nuestro juicio no se trataba de una personalidad de categoría menor o de un gestor de favores ocasionales de segundo orden "de poca o ninguna condición moral, egoísta" 75 como lo han definido algunos autores. Léase el

71. Epistolario, pp. 544-545.

72. AGS, Súplica de Manuel Mallo Quintana, Madrid, 12-XI-1792.

73. Podría tratarse del primer marqués de Zayas (o de su hijo), mariscal de campo de los Reales Ejércitos, héroe de Valetri, en Nápoles, comendador de Alcuesa, Caballero de la Orden de Santiago (1749-50) Berní y Catalá, José, Creación, antigüedad y privilegios de los títulos de Castilla, Málaga, Oficina del impresor de la divinidad episcopal, 1769, p. 282.

74. Llama la atención que Manuel Mallo ante su precaria situación en Madrid, pide al rey una «Ayudantía de pardos de las Milicias Regladas de Caracas», para evitar «su total ruina». AGS, Súplica de Manuel Mallo Quintana, Madrid, 20-I-1793. El mismo año, ante la negativa del rey de concederle una «tenencia veterana o ayudantía de pardos», Mallo solicita la plaza de cadete en el Batallón Veterano de Caracas, con éxito.

75. POLANCO, Tomás, Simón Bolivar: ensayo de una interpretación biográfica a través de sus documentos, Mérida, Biblioteca Digital Andina, (s/a), p. 49. 
encarecido interés de los Palacios en que Antonio Mallo contara con todas las comodidades para su nuevo proyecto de vida en Nueva España:

"Con esta misma fecha escribo a don Antonio Mallo a quien han hecho Superintendente de la casa de la moneda en México, y le incluyo una para ti y por tu ausencia a los demás hermanos con letra abierta para que tengáis a su disposición cuanto dinero necesite para su viaje, contando con lo que yo tengo allá, y si no tengo nada he contado con lo tuyo y lo de los demás hermanos confiado en nuestra unión y correspondencia, no tengo para qué encarecerte esta recomendación pues que a primera vista sabes las muchas obligaciones que debo a su hijo y amigo mío a quienes debo toda felicidad del día (...)"76.

Manuel Mallo empezaba a vincularse a la red del poder cortesano desde el 12 de marzo 1798: "Para Mayordomo de Semana de mi Real Casa nombro a Dn. Manuel Mallo de Quintana y Dn. Joaquín Melgarejo y Sauxin. Tendréislo entendido y dispondréis lo correspondiente a su cumplimiento"77. También obtuvo una pensión vitalicia de 650 pesos fuertes anuales y otra para sus hermanas.

En relación a Antonio Mallo contamos con una información valiosa que transparenta claves del contexto de los Mallo como familia y asimismo el viaje atlántico propiamente. Se trata de su mujer, Benedicta Quintana, quien desea en 1799 ir a España y pide "auxilios para mantenerse". Tal petición la avala y apoya Antonio López Quintana (amigo y aliado de Esteban Fernández de León, personaje clave de los saavedranos en Caracas) para entonces intendente de la provincia de Venezuela. A lo largo de esta carta ${ }^{78}$ enviada al secretario de hacienda Miguel Cayetano Soler, destaca esa extraña mixtura "pública-íntima" que hemos notado en la documentación sobre los Mallo. En el entorno de funcionarios de confianza del rey se interesan por la suerte de Benedicta y en cartas de Saavedra a Gálvez se advierte situaciones similares, como el hecho de que el entonces intendente caraqueño informe a Gálvez sobre los problemas maritales del matrimonio Mallo-Quintana.

En ese viaje Benedicta planeaba pasar a España con sus cuatro hijas y un hijo (Rosa, María Antonia, Josefa, Agustina y José) este último estudiaría en el

76. Carta de Esteban Palacios a Carlos Palacios del 10-II-1799. Epistolario, p. 548. A propósito del parentesco de Antonio Mallo con Manuel Mallo, leyendo la carta de Esteban Palacios, se trata de padre e hijo respectivamente, sin embargo, Demetrio Ramos se confunde y los ubica como hermanos. Ver RAmos, Demetrio, «A los dos siglos del viaje a España de Simón Bolívar. La causa y su deseo de instalarse en la corte para algo muy distinto que la carrera de armas», Boletín de la Real Academia de la Historia, t. CXCVI, cuaderno I (1999), p. 14.

77. Aranjuez, 12-III-1798, Marqués de Santa Cruz, caja 610, exp. 26 (AGP).

78. Carta de Antonio López Quintana a Miguel Cayetano Soler, Caracas 3-IX-1800. Leg. Caracas, 515. (AGI). 
Real Colegio de Artillería de Segovia ${ }^{79}$. Es sugerente que el rey se interesara tanto por su suerte. Esto abre la posibilidad de fortalecer la teoría de una breve suerte cortesana de Manuel Mallo ¿por qué tanto interés en la suerte de los Mallo-Quintana? Según nos dicta la documentación ${ }^{80}$ Antonio Mallo abandonó a su suerte a Benedicta Quintana para marchar a México. Una situación similar como vimos en otra carta, ocurrió en la década de los ochenta del dieciocho. No obstante, el interés que eso suscitaría en las altas esferas en Madrid, es poderosamente llamativo.

Cuando Francisco de Saavedra fue nombrado ministro de Estado, Manuel Mallo actuó como una suerte de valido de la reina, cosa que los panfletos y libelos de la época no dejaron pasar de largo, recreciendo un rumor de infidelidades de María Luisa de Parma con este payanés, eco que llegó incluso a los predios de la historiografía ${ }^{81}$. Manuel Mallo mudó su residencia a una casa

79. Copia de la anterior, Leg. Caracas, 515 (AGI).

80. «Por la adjunta Real Orden aportoría [sic] se enterará V.S. de la resolución de S.M. que entregará a D. Antonio Mallo sino se hubiese embarcado para México y le franqueará cuantos auxilios acaso necesita al fin de verificar con su mujer e hijas su viaje en derechura a la Coruña. O a cualquiera de los demás Puertos de Galicia para les sea menos penoso el pasar a su patria. En el caso de que D. Antonio Mallo se hubiese embarcado sin su mujer e hijas para México quiere Su Majestad que sin pérdida de la primera coyuntura las haga V.S. embarcar y dirigirse precisamente a los enunciados Puertos de Galicia a reunirse con el Padre de la misma familia de quien no es la voluntad del rey se separen». AGI, el mismo cuadernillo firmado (una minuta de varias representaciones de Benedicta y las respuestas del rey -copias-) por Antonio López Quintana, Caracas 27-III-1800, 1-IX-1800. Leg. Caracas, 515.

81. Como señala Carlos Pereyra, «María Luisa de Parma ha tenido siempre "mala prensa". Hasta los poetas le han negado su benevolencia, pese a ser la poesía muy inclinada a perdonar ciertas faltas». Véase a Pereyra citado por Carlos Seco Serrano en su estudio introductorio de las Memorias del Príncipe de la Paz, Madrid, Ediciones Atlas, vol. I (1956), p. xxix; ver también PEREYRA, Carlos, Cartas confidenciales de la reina María Luisa y de don Manuel Godoy, con otras tomadas del Archivo reservado de Fernando VII, del Histórico nacional y del de Indias, Madrid: 1935; Calvo maturana, Antonio, «Eva y la pérdida del paraíso imperial: alegorías misóginas de María Luisa de Parma en el siglo XIX», Reales Sitios, no 167 (2006) pp. 68-77; y de este mismo autor: «María Luisa de Parma: reina de España, esclava del mito», Granada, UGR, 2007, pp. 149-150. Los testimonios de dos figuras políticas tan influyentes entre 1799 y 1801, como Godoy y Urquijo, y la memoria histórica de Andrés Muriel, contribuyen a ubicar a Manuel Mallo en los predios del poder. Andrés Muriel relata que «por entonces era voz pública que galanteaba a la reina un guardia de Corps llamado Mallo, natural de Caracas, joven de agradable semblante. Pero aunque logró algunas distinciones y entró a ser mayordomo de semana, nunca llegó a tomar parte de los negocios públicos, ni perjudicó en nada al ascendiente y poderío de don Manuel Godoy. Se cuenta que lejos de asustarle éste con la presencia del favorito rival, que seguía al parecer sus huellas, le miraba con indiferencia. Estando asomados a uno de los balcones del palacio San Ildefonso un día el rey y la reina y el príncipe de la Paz, atravesó Mallo la plaza en una vistosa berlina tirada de caballos ricamente enjaezados. "¿Quién va dentro de aquel coche tan brillante?», dijo el rey. «Es Mallo», respondió el príncipe de la Paz. "Y dónde le ha venido de 
contigua al Palacio Real, lugar que fue, como hemos dicho, primera residencia de Simón Bolívar en la villa y corte. Por ende, era la misma casa que compartió Palacios con Mallo, de la que el primero se mudó al tiempo que arribaran a Madrid su sobrino y su hermano ${ }^{82}$. No hay que olvidar el hecho de que Palacios también fue alférez de caballería de la Guardia de Corps, el círculo militar más cercano al rey. Es decir, cada quien explota las relaciones en la medida de la densidad y eficacia de éstas, a la vez que en ocasiones convergen los núcleos nodales de cada una, como este caso: varios elementos se congregan alrededor de Francisco de Saavedra, del círculo de Saavedra.

¿Cuánto poder efectivo tenía el payanés Manuel Mallo? Ostentaba un poder condicionado a sus circunstancias en la corte que al parecer era más efímero y breve de lo todos esperaban. En carta de agosto de 1799 de Pedro Palacios a su hermano Carlos Palacios en Caracas le escribe sobre la influencia de Mallo "más figurada que real y verdadera, y lo poco que hacía era con mucho trabajo y por el buen espíritu que lo rige" ${ }^{83}$, esto demuestra que había concebido mayores expectativas en la provincia venezolana de las que lograría cumplir finalmente en Madrid, con la llegada de Manuel Mallo a la corte y la aparente

repente tanta ostentación?", volvió el rey a preguntar. «Parece, señor -replicó el príncipe de la Paz-, que corteja a una vieja ruca y que ésta le ha puesto en zancos». MURIEL, Andrés, Historia de Carlos IV, t. I, Madrid, Ediciones Atlas, 1959, p. 36; León y Pizarro, en sus Memorias, observa el desaire de Urquijo ante la figura de Mallo: «empezaba (...) a afianzarse el favor privado del guardia de Corps americano don Manuel Mallo (...) Urquijo trataba a Mallo con desaire (...) sin temeridad, podría asegurarse que la poca robustez de su fibra fue la única causa que le privó de un favor más decidido (...) porque la propia idea de la debilidad del sujeto, apoyaba acaso en informes que se tomaban, antes hiciese por la otra parte alejar la intención con el deseo». LEÓN Y PIZARRO, Memorias..., t. I, p. 79. Es obligatorio entonces comentar el rumor más sonoro en la memoria histórico-colectiva de María Luisa de Parma, para ir dejando de lado el tema amoroso -que poco o nada interesa a los fines de este análisis- con la reina y el ascenso de Godoy en relación a un affaire con ella. Vale mencionar varios elementos dentro del debate historiográfico: Luciano de Taxonera plantea que el primero en interesarse en Manuel fue Carlos, no María Luisa. Capturó su atención su espontaneidad, sinceridad y maneras de expresarse. Contemporáneos de Manuel Godoy como Lord Holland, Alcalá Galiano y Bourgoing coinciden que Godoy sobresalía en su forma original de expresarse, modales llenos de gracia, su «encantador» toque de «indolencia» y una elegancia natural que llamaba la atención. Asimismo no era el personaje tosco, zafio e ignorante que siempre se ha dicho, amparado en la falda de la reina. Al cabo de varias lecturas, se concluye que hubo un efecto, aunque poderosamente atípico, psicológico, sobre unos monarcas atacados e intrigados desde temprano por las facciones de poder en corte. Godoy representó, ciertamente, una lealtad que nunca sintieron en Aranda ni en Floridablanca. Por ello, el extremeño asciende por encima de los partidos «aragonés» y «golilla», fue la única estrategia que a Carlos IV le valió para superar esa guerra de facciones. Ver la PARRA, Emilio, «La inestabilidad...», pp. 23-34.

82. BEERMAN, Eric, «La pintoresca...», p. 1091.

83. Epistolario, p. 555. 
posición de su hermano Esteban Palacios. Esas perspectivas se desdibujaban en la medida que disminuía el poder de Saavedra y por consiguiente el de Manuel Mallo.

Manuel Mallo fue un "favorito de los tiempos goyescos" que en repetidas ocasiones cayó en desgracia política. Vivió varias veces la cárcel a partir del nuevo advenimiento de Godoy "(...) cuando por fin fueron perdonados los culpables de la Causa del Escorial, decide tomar partido contra Godoy, por lo que interviene en los sucesos del 19 de marzo de 1808, en Aranjuez" ${ }^{84}$. También luchará contra los franceses. En una carta fechada el 22 de septiembre de 1815 en Astorga se defiende de las acusaciones del intendente de León; relata cómo fue su experiencia militar en la resistencia contra la ocupación francesa y menciona cómo el rey busca entonces reconocer a los colaboracionistas con Francia:

“(...) El Rey Nuestro Señor desea saber cuales Empleados en sus Rs. Ventas, y cuales sirvientes de SS. AA. dominados por los enemigos vivieron entre ellos, y tomaron partido con ellos, faltando à los deberes de amor y fidelidad hacia la Patria y S.R.M. Yo antes de la invasión enemiga estuve distante de esta Provincia, preso por la causa del Escorial en el Castillo de San Antón: salí de la prisión desterrado à Tuy; y una orden circular de S.M. mandando poner en libertad a los sindicados en ella, me libertó del destierro: regrese a mi Casa: pero ya en los tristes momentos, en que el pérfido Napoleón arrancó a S.M. del Zeno de su Reino, y del de sus Hijos y Vasallos: viéndose estos sin tener quien los gobierne instalaron sus Juntas gubernativas; y deseando Yo sacrificarme por la Patria, y mi venerado Amo y Sor. Fui el primero que pedí a la de León me destinase al Ejercito; esta agradeció mi instancia. En vista de esto represente con el mismo objeto al Gral. Cuestas que lo era de Castilla, quien me eligió por su primer Ayudante de Campo; y desde entonces ni volví à esta Provincia, ni vi a los enemigos, sino en los campos de batalla y con las Armas en la mano. Derrotado el Ejército en que militaba en Veles, me dirigí à Sevilla deseoso de unirme a los pequeños y dispersos restos que habían quedado del mismo, ó à cualquiera otro: una reforma que extinguió el Regimiento en que me hallaba me quito el dulce anhelo à que ansiaba. La Junta Central existente en esa no me destino; y con esperanzas de conseguirlo seguí al Gobierno a Cádiz, permanecí cerca de el hasta su regreso al centro del Reino, que se verificó cuando los invasores no pisaban el territorio Español. Por consecuencia clara ni pude ver quienes tomaron partido con los franceses, ni Yo pude tomarle, pues estaba muy lejos de ellos. El mismo Intendente muy bien lo sabe; y si se hace que lo duda, ¿Por qué no procede según S.M. le ordena? ¿Espero acaso que el Reo se delate?, y ¿cual será este que diga: Yo necesito

84. Miramón, Alberto, Dos vidas..., p. 59. 
clarificarme. Estoy cierto que de los que hayas, si a cada uno se le pregunta por una Carta, ninguno diría que si" 85 .

Y tras su regreso como mayordomo de semana en 1814, luego de tiempos de destierro en Guadalajara, Astorga y en León, Manuel morirá el 7 de mayo de 1838:

"Habiendo fallecido el Mayordomo de semana de S.M. Don Manuel Mallo el día 7 del corriente, creemos de nuestro deber como sus secretarios elevarlo al conocimiento de V.E. para los efectos oportunos. Con este motivo y debiendo disponer se celebre el funeral correspondiente por el alma de dicho Sr., esperamos que V.E. se sirva manifestarnos si tiene a bien permitir el que, como jefe, se encabecen a su titulado las esquelas del convite. (...) Juan de Guardamina, José Rodríguez. Madrid 9 de mayo de 1838"86.

A pesar de la poca valoración historiográfica que ha merecido este personaje, conviene que hayamos replanteado su estudio desde otros ángulos. Mallo encarnó, en su justa dimensión, los anhelos de un criollo americano en corte, tal vez blandido de una frivolidad política acorde con la época que vivía: fue un cortesano que jugó con claridad sus cartas al tanto de sus limitaciones, si acaso las tenía, como tanto insisten algunos autores. Su vertiginoso ascenso y el de los suyos dibuja las habilidades cortesanas del payanés-caraqueño para salir airoso de varias situaciones políticamente complejísimas. Arcesio Aragón cita las frías percepciones de un diplomático sobre Mallo, que caben en este balance:

"Su nulidad, escribió un diplomático francés, conviene mucho a la Reina que tiene verdadera ansia de gozar de la autoridad que ha recobrado, y al Príncipe de la Paz, que hastiado hace mucho tiempo de las funciones personales de amante oficial, ha podido consentir en tener un sustituto, pero no un rival. Mallo es mayordomo de semana, cargo que equivale al de nuestros gentiles hombres, que sirven cada cuarto de mes; se le paga en dinero que despilfarra en joyas, caballos y coches. Por lo demás, siempre rodeado de espías, y sin libertad para reunirse con nadie, especialmente con mujeres, es sin duda el hombre más desgraciado del mundo, porque es difícil concebir que pueda encontrar su dicha en el ejercicio de sus funciones" 87 .

Se revela en una carta de los Palacios Blanco que Mallo fue fiel a la amistad con ellos, pues lo hace "con mucho trabajo y por el buen espíritu que lo rige" 88 . Sin embargo no olvidemos que hubo un momento en 1800 que tenía todas las circunstancias favorables en la corte justo cuando su influencia lograba crecer:

85. Expediente personal, caja 610, exp. 26 (AGP).

86. Carta al marqués de Valverde, mayordomo mayor de S.M., caja 610, exp. 26. (AGP).

87. ARAGÓN, Arcesio, Fastos payaneses 1536-1936, t. XV, Bogotá, Editorial Imprenta Nacional, 1940, p. 293.

88. Epistolario, p. 555. 
"Con la creciente y reconocida influencia de este payanés, el ministro de Francia Luciano Bonaparte llegó a Madrid el 2 de diciembre de 1800, en misión de información a su ilustre hermano sobre la situación política de España, y de entablar relaciones con Mallo como posible ministro de Estado, en reemplazo de Mariano Luis de Urquijo, para prevenir el regreso a este cargo del príncipe de la Paz (...) Aparentemente Mallo no impresionó demasiado al hermano de Bonaparte, ya que un pariente de Godoy, Pedro de Ceballos, fue nombrado para reemplazar a Urquijo"89.

En carta del 22 de agosto desde Madrid, Pedro demuestra la información política y cortesana que maneja cuando le escribe a su hermano Carlos sobre Urquijo: "El vulgo cada día muda a los Ministros, pero no se ven sus efectos lo que se dice es que Urquijo que era el primer oficial de la Secretaría de estado sigue despachando en calidad de Interino y que ahora le han declarado el sueldo en calidad de propietario y aun se dice que lo continuarán" 90 .

\subsection{Ignacio Canibell y Francisco José Bernal: dos miembros del Círculo en constante movimiento}

Esteban Palacios en una carta que remite a su hermana envía "muchas expresiones a Canibel"91. Esto nos invita a profundizar un poco en este personaje de sugerente estampa y leal miembro del Círculo de Saavedra. Ignacio Canibell -como lo hemos referido anteriormente en su breve ficha- fue amigo de Esteban y fiel funcionario de Saavedra. Valiéndose de la vieja amistad de Canibell con Saavedra como secretario de Estado, el gobernador de Venezuela Pedro de Carbonell, comisionó (en 1798) a Canibell para llevar ante el rey los papeles que informaban detalladamente sobre la conspiración de Gual y España de $1797^{92}$.

En el camino Canibell es apresado por un ataque de piratas. Salva la vida y desde Lisboa escribe para que le faciliten ayuda económica a través del encargado español en Portugal ${ }^{93}$, confiado en que su antiguo jefe Saavedra era todavía secretario de Estado y que le prestaría toda la ayuda necesaria para

89. BEERMAN, Eric, «La pintoresca...», p. 1093.

90. Epistolario, p. 557.

91. Ibid, p. 489.

92. La conspiración de Gual y España es el primer movimiento organizado de la América española que plantea los principios republicanos con un importante trasfondo radical, de igualdad de razas, muy inspirado en la revolución francesa. Entre los conspiradores fue determinante la participación de los conspiradores liberales españoles de San Blas, presos en el cuartel San Carlos de La Guaira. Este episodio conmocionó profundamente a la sociedad mantuana caraqueña y tuvo un espinoso eco entre las autoridades españolas, por ser un grave precedente de la situación de los reinos de indias a punto de girar hacia la independencia y las conjuras republicanas.

93. Carta de Ignacio Canibell al rey y Secretarios de Estado, Lisboa, 25-V-1798 (AGI). 
llegar a España. Su sorpresa es cuando Mariano Luis de Urquijo le notificaba -en lugar de Saavedra- que el encargado de negocios en Lisboa Antonio Domingo Porlier, estaba preparado para facilitarle el pertinente pasaporte para entrar a Madrid y le suministraba, a cuenta de su sueldo, el dinero que le solicitase bajo recibo. Todos los gastos corrían a costa de Canibell. Parece que interesaba poco que la comisión fuese de trascendente importancia para la seguridad y la estabilidad de la provincia; daba lo mismo informar al rey "a viva voz" de todo lo ocurrido en La Guaira y en Caracas respecto a la conspiración de Gual y España, el primer intento independentista de gran envergadura en la región.

En otra carta del 25 de mayo de 1798 escribirá Pedro Carbonell desde Caracas al nuevo primer secretario de Estado Manuel Godoy, sobre las loables características del emisario Canibell, así como de su relación de trabajo y confianza con Francisco de Saavedra: "sujeto de toda confianza del Excelentísimo Dn. Francisco de Saavedra, cuando fue Intendente en ella, y por el acierto de su desempeño en el empleo de Contador Mayor desde enero de 1791 hasta el presente y de varias importantes comisiones del servicio que se le han confiado, por su fina crianza e inteligencia en sus costumbres e idiomas extranjeros (...)"94.

Ignacio Canibell pertenecía al círculo saavedrano en Caracas, como ministro contador mayor del tribunal de cuentas de Caracas dejado por el sevillano, deducimos que su lealtad superaría los avatares políticos en la provincia una vez que Saavedra marchara de regreso a la metrópoli. Podemos inferir que en 1798 se unirá al resto del círculo en la metrópoli. Las diligencias cortesanas de Canibell no sólo se limitaban a dar noticias sobre la sublevación en La Guaira y Caracas, también traía consigo una vieja molestia por resolver en la corte. Desde 1793 acarrea Canibell un problema, un altercado con Antonio López de Quintana, oidor decano regente de Caracas. Al parecer Quintana humilló públicamente a Canibell a la salida de una ceremonia eclesiástica "una función de Iglesia" por un gesto de éste al comienzo del ceremonial.

Francisco José Bernal fue un curioso miembro del Círculo, ciertamente un miembro en movimiento. Su carrera comenzó en Riohacha (Colombia) de la mano del virrey Flórez. Estos detalles se recogen en la breve ficha del epígrafe 4.1. Este personaje se relaciona con el Círculo a partir de los vínculos familiares que trama con el mantuanaje local, entroncando con los Clemente y Francia (casa con una hija de este patriarca) y los Palacios y Blanco. Más tarde, ya en

94. Carta de D. Pedro Carbonell al rey Carlos IV y al Primer Secretario de Estado, D. Manuel Godoy Príncipe de la Paz, Caracas, 25-V-1798 (AGI). Las cursivas son nuestras. 
corte, fortalece su participación en el Círculo de Saavedra -posiblemente menos directa que los Palacios o los Mallo- por medio de operaciones burocráticas, comerciales, de asistencia y de solidaridad con sus paisanos y fueron posibles gracias a la consanguinidad por medio de su esposa Rafaela, hija de Mercedes Palacios y Xerez. Debemos fijar la vista en que Bolívar -miembro protegido de los Palacios y Blanco y del Círculo saavedrano- cuando viaja a España sólo trae obsequios para la hija de Francisco Bernal y Rafaela Clemente Palacios.

El trato de Bernal con Concepción Palacios era muy cercano. Para Simón Bolívar tenía que ser más que un gesto correspondiente a los viejos y entrañables afectos de la familia, era además la llave para continuar abriendo puertas en la metrópoli. Durante 1799 -año que llega Bolívar a España- Bernal exponía al rey que en 1796 vino en compañía de su esposa Rafaela Clemente, de su hija de tres años, Fermina Bernal Clemente, y su suegro, el coronel del Ejército Manuel de Clemente y Francia, a estos reinos y que "como poco tiempo después se declaró la actual guerra con Inglaterra no ha sido posible el regreso a su casa" por lo que suplica "se digne a concederle licencia por dos años con el goce del sueldo (...) para venir a España" ${ }^{95}$. Ansiaba unirse a su familia en la metrópoli.

Bernal nos demuestra también que había fisuras en el Círculo. Detestaba al circunstancialmente poderoso Manuel Mallo porque éste no fue especialmente solidario con Bernal, como sí lo era con Esteban, Carlos, Pedro Palacios o Simón Bolívar: "Las [hermanas] Mallo salieron de Cádiz en diciembre para venir a Santiago, pero aún no han llegado, el señor don Manuel permanece en la Corte y para mi como si se hubiera muerto pues no le he merecido la menor demostración de agradecimiento. Este es el mundo amigo don Carlos"96.

Este enfado de Bernal se debió a un favor no agradecido, a una deslealtad. Otro elemento que aparece en el trozo epistolar citado lo debemos comentar: la fecha, 31 de enero de 1802, pues nos sugiere una idea del ir y venir de Mallo en los intrigantes muros palatinos, pues como veremos más adelante para esta fecha, 1802, ya el Círculo de Saavedra ha sido atacado y desmembrado. No obstante, Mallo está aún -o ha vuelto- a la corte.

Vale comentar para cerrar este epígrafe, que cuando muere Concepción Palacios, su hermano Esteban vivía con Lino Clemente y Francia y Francisco José Bernal en la misma casa. Era otoño de 1792, tuvo que ser una noticia devastadora para Esteban. Apunta Bernal, su compañero de casa: "Esteban recibió

95. Francisco Bernal, licencia a España. Leg. 7185, 7 (AGS)

96. Ibid, p. 566. 
este disgusto al día siguiente de estar viviendo en compañía de Lino y mía que le ha servido de mucho consuelo de apartar de sí tan melancólica idea, sin embargo, de los extremos de sentimientos que le causó y que aún no deja de repetirlos frecuentemente" ${ }^{17}$. Este trío de paisanos, bajo el mismo techo en Madrid, nos dibuja parte del Círculo de Saavedra.

\section{La estela del Círculo de Saavedra en Caracas}

Veamos la nómina propuesta por Saavedra y aprobada por la Mesa de consulados: como prior el conde de Tovar, su teniente José Domingo Blanco, primer cónsul Juan José de Mintegui, su teniente Manuel de Clemente y Francia, segundo cónsul José De Escorihuela, su teniente Nicolás del Toro. Consiliarios hacendados el conde de San Javier, José Corcho de Iriarte, Feliciano Palacios y Sojo, Andrés Ibarra y Francisco García Quintana. Los tenientes de cada uno de los anteriores fueron Santiago de Ponte, Antonio Barreto, Martín Xerez de Aristiguieta, Fernando Ascanio, Manuel Monserrate. Los conciliarios comerciantes eran Manuel Felipe de Tovar, Juan José Echenique, Marcos Rivas, Juan Bautista Echezuría y sus tenientes respectivos Ignacio Gedler, Francisco Longa, Juan Benítez, José Joaquín de Anza y Blas del Castillo. Los conciliarios mercantiles fueron José Lázaro Rodríguez, y Antonio Orihuela y sus tenientes Pedro Delgado Correa y Miguel Carmona. Secretario Antonio Soublette, contador Gervasio Nava y el tesorero Jaime Bolet ${ }^{98}$.

Vale destacar que los principales nombres propuestos por Saavedra fueron Tovar, Mintegui, Clemente y Francia, [Gabriel] Bolívar y Ponte, Del Toro, Iriarte, Ibarra, Xerez de Aristiguieta y Palacios Sojo. Serán todos -salvo Mintegui- los padres, abuelos y tíos de los jóvenes mantuanos que viajan a España a hacer carrera militar, académica, comercial, política o simplemente la carrera vital, como la de Bolívar, que combinaba un poco de todas. A la par cabe decir que todos estos "principales" son miembros del Círculo de Saavedra en ambas playas atlánticas, con continua correspondencia humana, comercial y política entre la península y Caracas.

El 26 de abril de 1794, Esteban Palacios le escribe una carta importante al intendente de la provincia venezolana, Esteban Fernández de León -el más influyente miembro del círculo de Saavedra en la faz atlántica criolla- protegido y recomendado del sevillano. La carta resume la inestable situación y el contexto

97. Ibid., p. 501.

98. Álvarez, Mercedes, El Tribunal del Real Consulado de Caracas. Contribución al estudio de nuestras Instituciones, t. II, Caracas, Ediciones del Cuatricentenario de Caracas, 1967, pp. 71-89. 
acalorado de la intendencia en Caracas y su eco en la corte tras el fallecimiento de Cubells, el intendente dejado por Saavedra después del breve período del mismo gobernador Guillelmi. A la muerte de Cubells se suscita una guerra por el cargo entre el gobernador y el asesor de la intendencia, Rafael Alcalde. Tras una larga controversia y choques de ordenanzas y de reglamentos de intendentes (el de Buenos Aires ${ }^{99}$ ) es nombrado por Real Orden Esteban Fernández de León como intendente con carácter interino, por recomendación de Saavedra, con el objetivo de mantener ciertas precauciones respecto a la opinión pública caraqueña y la fortuna de los Fernández de León ${ }^{100}$.

Saavedra confía en su antiguo aliado, al punto de recomendarlo para que a la vez que ejerza como intendente, mantenga su cargo de doce años ha, al frente del "Ramo del Tabaco". Recordemos que Esteban Fernández de León fue intendente desde 1793 hasta 1802. La carta recrea bajo el prisma de la amistad y la alianza política un breve espacio de ese período de conflictividad alrededor de la intendencia caraqueña:

"Al Señor Intendente (...) Muy estimado señor mío y mi dueño: A la triste noticia que tuve de la muerte de mi padre, que Dios Haya, tuve también el gusto de saber la buena compañía que en sus últimos días quiso V.S. dispensarle tomando parte en este sentimiento por un efecto de su generosidad y buen corazón: esto me ha sido sumamente grato y me impone la obligación de tributarle las mayores gracias aunque con el desconsuelo de considerarme inútil en obsequio de V.S. Que importa que en varias ocasiones ocurridas en esta corte, se haya vuelto por la justicia de su causa, en contra de algunos émulos que no faltan a los que mandan cuando esto es y debe ser en honor de la verdad? Yo estoy firmemente persuadido que todas son inútiles gestiones de sujetos que solicitan reunir en una mano todo el mando para hacerse unos perfectos déspotas y conciliar su interés particular. Estoy seguro de esto y también del gran concepto que tiene V. S. en la corte con los principales resortes del Ministerio de su mando, por lo que desprecian altamente todas esas bagatelas. (...) Yo me hallo en el día de Guardia de Corps de la nueva compañía, ya en este destino, como cualquiera otro, me protesto ser su mayor servidor y amigo"101.

En esta época, próvida políticamente, los caraqueños en corte dirimían interesantes asuntos de poder en las dos playas atlánticas. La influencia del círculo de Saavedra tenía sus reflejos en una y otra parte del reino, en el centro y en los extramuros. No podrá verse, posiblemente, un momento político como

99. ANDREO GARCÍA, Juan, La Intendencia..., pp. 70 y ss.

100. Ibid.

101. Epistolario, p. 523. 
éste. Al menos un personaje como Esteban, no viviría otra vez circunstancias en la corte tan favorables como breves. Por un lado manejaba muy bien qué es lo que se está discutiendo a puerta cerrada en la secretaría, respecto la situación de la intendencia caraqueña, y cómo soplan a favor los vientos. Concluye Esteban, que ya está creada la nueva compañía americana de guardia de corps, que él forma parte de ella y que claro, está puesto a las órdenes del intendente y amigo, en este nuevo destino. Era una época dorada donde, como suele ocurrir, este mantuano Palacios todavía no caía en cuenta de lo fugaz que sería.

Otro reflejo del poder -y de la buena voluntad hacia sus prosélitos caraqueños- de Saavedra queda evidenciado en una carta del año 1797, donde Carlos se describe como presa de los ataques del gobernador/capitán general Pedro de Carbonell. En ella señala a estos "Jefes de América que nos mandan como déspotas seguros de la distancia que hay a la Soberanía, pero atrás nuestras quejas", y lo más sugerente: "yo me acercaré a la Secretaría a informarme de algún amigo si acaso ha llegado, y con el motivo de la actual guerra supongo no vendrá el nuevo Gobernador aquí con la brevedad que Vmd. se propone"102. Francisco de Saavedra, nuevamente, mostraba una correspondencia solidaria con sus antiguos aliados, ya tenía dos meses como Secretario de Estado y leemos que había gestionado un cambio político en Venezuela, a favor de su círculo cisatlántico.

En otra carta de 1799, enviada desde Madrid por Pedro Palacios a su hermano Carlos, ratificamos todas estas ideas anteriores. El gobernador que sustituyó a Pedro de Carbonell era Guevara de Vasconcelos, amigo de los Palacios: "Por lo que mira al Gobernador es necesario que hayas continuado su amistad en los términos que posible sea entre un súbdito y un gobernador de América, pues si acaso no lo has hecho así no han correspondido con lo que ha tratado con Esteban antes de su partida"103. En la misma carta, Pedro comenta que ha conocido por vía de Esteban al hermano de Guevara de Vasconcelos y aprovecha para contarle la buena nueva que ante la posibilidad de haber reemplazado a Esteban Fernández de León en la intendencia caraqueña, por el "Intendente Garrido", salió una contraorden y éste no pudo embarcar en Cádiz hacia Caracas, lo cual “está muy bien, ya que sale nuestro Don Esteban de León”104.

Estos episodios en torno a Saavedra, el intendente Fernández de León, Esteban, Pedro y Carlos Palacios, nos están informando sobre resultados de una dinámica cortesana con efectos en la doble faz atlántica, por lo que no se pueden ajar como éxitos palatinos. Sin olvidar: a la sombra y buena protección de Francisco de Saavedra, a punto de la retirada.

102. Ibid., p. 536.

103. Ibid., p. 551.

104. Ibid. 


\section{Desarticulación y soledad: el oscurecimiento de Saavedra}

Francisco de Saavedra, como hemos dicho, fue un entusiasta de la aristocracia criolla y el papel que podrían jugar los americanos si se les tomaba en cuenta en los espacios de formación, de poder político y propiamente en la misma corte. Favoreció, como vimos, la carrera del cubano Arango y Parreño y hasta donde hemos podido escrutar, la de los Palacios Blanco y toda la cartografía que se despliega en los predios de este pequeño universo de mantuanos en Cádiz y en Madrid. De la mano de Saavedra caminaron personajes con peso político en la provincia de Venezuela, como Ignacio Canibell, y Esteban Fernández de León, quienes representaron la influencia, todavía latente, del sevillano en Caracas, en su ordenamiento político en torno a la intendencia, consulado y ayuntamiento. Como ya se habrá leído, hemos denominado a ese fenómeno como un círculo, un círculo de influencia, de prestigio y de poder. Esta órbita de aliados además de ser un legado del sevillano traducido en los hombres que directa e indirectamente quedan funcionando política y administrativamente en la maquinaria colonial caraqueña, es también un espacio que el sevillano, desde la corte, controla afinadamente. En una carta de 1799 de Esteban Palacios a su hermano queda patente esta idea: "El nuevo intendente nombrado para esa no llenará nunca en mi sentir el hueco de León, pero lleva bastantes instrucciones y como hechura de Saavedra es menester que cuanto haga sea por dirección suya, tiene instrucción y talento, y le conozco particularmente"105.

De forma similar, aunque menos eficaz por lo competido y crítico del mundo cortesano, Manuel Mallo y Esteban Palacios (y junto a ellos su cartografía propia de amigos y familiares) en la España-corte, son las cabezas visibles del círculo de Saavedra. Esa asociación dependiente de la fortuna, los contactos y de los ritmos cortesanos, estaba centrada en el sevillano y su suerte durante la época más crítica de la política del reino: las relaciones con el Directorio, la inestabilidad atlántica, las pugnas cortesanas, la legitimidad del gobierno progresivamente venida a menos, del trinomio de los monarcas y Godoy. Todo ello hizo que el goce de los cargos dependiera de las figuraciones, las conjuras

105. Epistolario, p. 547. Juan Andreo García apunta, con toda certeza, que Esteban Fernández de León fue intendente desde el 16 de diciembre de 1793, «continuando así el período más largo en el que un mismo Intendente regirá los destinos de la Real Hacienda Venezolana» hasta finales de junio de 1802. No obstante Esteban Palacios escribe con nostalgia la aparente remoción de Fernández de León, pero su hermano Pedro notifica el cambio de planes que hubo «El Intendente Garrido que ya estaba en Cádiz para embarcarse para esa [Caracas], ha salido una orden para que no. Le he dicho a Esteban que en el Reg. está muy bien ya que sale nuestro Dn. Estev. de León (...) los deseos son muy buenos pero todo tiene sus dificultades». ANDREO GARCÍA, Juan, La Intendencia..., p. 72; Epistolario, p. 551. 
y las tramas políticas en un escenario donde nada era lo que parecía ser y todo podía tornarse impredecible, cuando no arbitrario. Saavedra encumbra en cierta medida, emplazado por las circunstancias de la crisis cortesana, su prestigio como hombre ilustrado (como el de Jovellanos, "Gentes de razón"), representaría un alivio para la opinión pública ante el inminente naufragio político que amenazaba acontecer con el trío aludido. Le escribió la reina a Godoy: "(...) es cierto que hay muchos descontentos y que siempre que algo hubiese seríamos los tres las primeras víctimas" 106 .

Este es el contexto donde Saavedra pudo ser un favorecedor de nuestro grupo y sobre todo de los Palacios (basados en su Epistolario). En 1789 se le designa al ilustrado sevillano una plaza en el Supremo Consejo de Guerra. Hasta 1797 actúa, según calcula Morales Padrón, "como un funcionario o burócrata más de la capital del reino" 107 , pero con profuso prestigio y relaciones cisatlánticas, pues es en este período en el cual más se activa su favor hacia los Palacios y su amplia cartografía de mantuanos. A partir de 1797 como ministro de Hacienda y en marzo del año siguiente secretario de Estado, es cuando ocurre un clímax cortesano para los mantuanos del círculo saavedrano; y como un clímax, la caída será estrepitosa. Este lapso es cuando más, en palabras del sevillano "los enemigos combaten continuamente" 108 , pues la política -y más la cortesana de Carlos IV- se regía por vientos de diversos orígenes que hoy soplaban cálidos hacia una dirección y mañana, lo harían fríos, en la contraria ${ }^{109}$, sin previo aviso de tempestad en cierne. El choque de estos frentes opuestos llevó a Saavedra a dimitir de su cargo. Fue determinante la acometida de Manuel Godoy ${ }^{110}$ contra el sevillano, pero no podemos dejar de lado el hecho de que Saavedra,

106. Carta de María Luisa a Manuel Godoy en 1799 , cit. por LA PARRA, Emilio, La alianza de Godoy con los revolucionarios. España y Francia a finales del siglo XVIII, Madrid, CSIC, 1992, p. 179.

107. morales PADrón, Francisco, Diario de don Francisco de Saavedra, Sevilla, Universidad de Sevilla-CSIC, 2004, p. 12.

108. Ibid.

109. Godoy, al principio, seguidor del Directorio, luego hará un giro hacia los sectores más conservadores de la corte, cuando se percata en 1798 que su caída política había sido motivada por la carencia de apoyo del gobierno francés. Cuando son llamados Saavedra y Jovellanos (después Urquijo) a encabezar el gobierno, por ilustrados y afrancesados, el príncipe de la Paz calcula una alianza con los partidarios de Inglaterra (cautelosamente se acerca a Osuna y a otros poderosos), con la Iglesia, la Inquisición, y, su astucia, le ayudó a captar «al vuelo el cambio operado en Francia tras el $18 \mathrm{Bru-}$ mario», el hombre fuerte de Francia, Napoleón, esperanzaba en España, la restauración monárquica en la vecina nación que superaba el trauma revolucionario. Los cambios de rumbo eran impredecibles, porque se dictaban desde la conjura y la conspiración palaciegas. Ver LA PARRA, Emilio, La alianza..., p. 180.

110. Por razones de espacio no podemos incluir un apartado correspondiente a los ataques del duque de la Alcudia contra Saavedra, sin embargo, dejamos algunas referencias 
prudentemente, deja la corte y se retira a Andalucía, todavía gozando de un lugar en el Consejo de Estado. Su recogimiento tuvo que significar en 1799, necesariamente, el desamparo, la oscuridad, la soledad y la ruina de sus antiguos favorecidos, ahora, enfadados y resentidos de cara a la orfandad cortesana en medio de una grave crisis. Esteban en clave íntima y reservada dejará sobre el papel sus pensamientos:

"Hay una multitud de acontecimientos que no es posible decirlos, sólo basta decirte que Saa... es un hombre execrable, esta proposición escandalizará al que se la digan en esa, y yo pido se reserve. Estoy lleno de los sentimientos más tiernos hacia los míos y de mi país, sólo desearía ser algo para obrar si hubiere alguno tan injusto que me crea desleal e indolente, nada me importa, mi proceder no me acusa de nada y hasta ahora me he conducido como me conviene"111.

No es difícil decodificar esta especie de acróstico "Saa" para comprender que se refiere a Saavedra. Llenando los renglones ocultos de la carta y a sabiendas que el último cargo que disfruta Esteban en 1799 en la contaduría de la Real Hacienda le llegó gracias al favor del sevillano, su enfado es casi natural, lo han dejado solo en un lago de tiburones. Pero más sugerente es la petición que hace a Carlos de cautela con esta "proposición" de que "Saa es un execrable", pues escandalizará en Caracas a quien la oiga, es decir, Saavedra tenía muchos adeptos en Caracas, su círculo saavedrano en esa ciudad es poderoso, los mantuanos cisatlánticos lo respetan y lo estiman y si Esteban Palacios emprende una campaña difamatoria con el otrora protector de mantuanos, quedaría desprestigiado en su ciudad natal.

Pedro Palacios, recién llegado a la España-corte, deja más palpable la situación; sin rencor hacia Saavedra, pues realmente no ha probado las mieles cortesanas brindadas por su favor, es mucho más claro, sincero, pragmático:

“(...) el apoyo sobre el que venía fundado que es Saavedra, está retirado en Sevilla, con que por ahora yo no aspiro a otra cosa que es a sacar algún partido

exactas para este aspecto: LA PARRA, Emilio, La alianza..., pp. 178-179; LA PARRA, Emilio, Manuel Godoy. La aventura del poder, Barcelona, Tusquets, 2005, pp. 208-209, 233 y 242-243; HeRMOSILla molina, Antonio, La enfermedad..., pp. 7 y 25-26; Mier, Fray Servando Teresa de, Memorias de Fray Servando Teresa de Mier. Del convento de Santo Domingo, de México, diputado al Primer Congreso Constituyente de la República Mexicana, Madrid, Editorial América-Biblioteca Ayacucho, 1917, pp. 208-209; MURIEL, Andrés, Historia..., pp. 36 y 52; LEÓN Y PIZARRo, Memorias de la vida del Excmo. Señor D. José García de León y Pizarro, vol. I, Madrid, Revista de Occidente, 1953, p. 79; Godor, Manuel, Memorias de Don Manuel Godoy Príncipe de la Paz. Memorias críticas y apologéticas para la historia del reinado de señor don Carlos IV de Borbón, t. II, Madrid, Imprenta de I. Sancha, 1836, pp. 127, 155, 156, 128, 129, 139, 141, 158, $159,307,331,333,334,357-359,363-366,374,377,390$ y 431.

111. Epistolario, p. 553. La cursiva es nuestra. 
sea el que fuere para ambos, según lo lánguido que advierto en el semblante a estas cosas, pues aunque hay favor se complica de tal manera que no es decible por la pluma; por otra parte Esteban se mantiene bajo aquellas primeras y moderadas impresiones que le fueron influidas por nuestro buen padre y según ello se gobierna en todo sin entrar en mucho manejo y travesura como lo exigen las circunstancias actuales, y por fin todo cuesta infinito. Yo me mantengo entrando poco a poco por ver si este u otro día puedo obrar con la eficacia que exige mi buen deseo (...)"112.

\section{Conclusiones}

Sin Saavedra poco se podía hacer en la corte. Saavedra era la protección que daba forma al círculo, sin el centro el radio desaparecía, desintegrando en su totalidad el diámetro caraqueño, en la complicada geometría cortesana finisecular.

El tiempo político de Francisco de Saavedra no culminó con la acometida godoyana de finales del XVIII, pues lo esperaban otras circunstancias políticas, apremiantes y exigentes de su capacidad como hombre de Estado. De nuevo, en la apuesta del poder, el sevillano coincide con Esteban Fernández de León (miembro del Consejo de Regencia), de su círculo de colaboradores y amigos durante y después de la intendencia de Caracas. Sabemos que Esteban Palacios será diputado suplente por Caracas en las Cortes de Cádiz ¿un último dibujo del círculo de Saavedra?

En poco menos de tres años antes (1809), Saavedra había sido llamado nuevamente como primer Secretario de Estado y del Despacho. El documento que citaremos termina de aclarar el papel histórico de Saavedra en atención con su deber político y patriótico, dentro de la crisis finisecular del reino. Más allá de su relación con los venezolanos, hemos visto el papel de este sevillano durante esta complicada época. Participó en los intentos de reorganizar la nación, como si se tratase de la última salida de cara a los momentos que reclamaban decisiones rápidas, al mismo tiempo que sabias. Godoy lo llama para prestigiar su proyecto, pero los reveses de la política condicionaron su actitud en virtud de lo que más convenía al reino. Esto significó la grave y peligrosa enemistad con el príncipe de la Paz (ahora "Príncipe de la Porra, Duque de la Tramoya y Señor de la injusticia", según una parodia de estudiantes de Cádiz ${ }^{113}$ ). Más tarde toma parte en la Guerra de la Independencia, preside la Junta Suprema de Sevilla y regresa, invitado por Fernando VII, el rey Deseado, a la primera Secretaría de Estado; siempre, en tiempos complicados:

112. Ibid., pp. 553 y 554.

113. LA PARRA, Emilio, "Godoy, prisionero de Fernando VII, marzo-mayo de 1808", Revista de Estudios Extremeños, no III (2001), p. 874. 
"Habiendo insistido Don Martín de Garay en la dimisión del encargo de la Primera Secretaría de Estado y del Despacho que interinamente desempeñaba, ha tenido a bien la Junta Suprema Gubernativa del Reino el admitírsela; y satisfecha de los señalados servicios que desde el principio de nuestra gloriosa revolución ha hecho a la justa causa de la nación Don Francisco de Saavedra, Secretario de Estado y del Despacho de Hacienda, además de estar convencida de la experiencia, luces y conocimientos políticos que ha acreditado a su dilatada carrera, y que unidos a su probidad y patriotismo le han granjeado la opinión pública, se ha dignado nombrarle en propiedad, a nombre del Rey, nuestro Señor Don Fernando VII por su primer Secretario de Estado y del Despacho. Teniendo entendido y lo comunicaréis a quien corresponda.

Marqués de Astorga Presidente. En el Real Alcázar de Sevilla a 30 de octubre de 1809. A Don Pedro Rivero, a Palermo, a Soler. A los virreyes y capitanes generales de América" ${ }^{114}$.

Francisco de Saavedra, con 72 años de edad, acude de nuevo a la convocatoria política. Su ciudad, Sevilla, ejerce un rol determinante durante la ocupación francesa. Se constituyó bajo su presidencia, y en su casa (los primeros días por la precaria salud del sevillano) la Junta Suprema de mayo de 1808, que tras la victoria de Bailén jugó cartas trascendentales en la partida por la independencia española. En la misma ciudad se instala posteriormente la Junta Central, una fórmula centralista de "organizar" la insurrección de las diferentes juntas provinciales. Instituida como Junta Suprema de España e Indias, la de Sevilla, de una manera precavida, ante la incertidumbre de qué ocurría en los reinos cisatlánticos, ofreció una especie de centro común de operaciones.

Apunta Manuel Moreno Alonso, en el estudio preliminar de su edición de los diarios de Saavedra, correspondientes a la rebelión de las provincias españolas entre 1808-1810: "Pues la Junta de Sevilla, que -después de la revolución "santa"- nombró por su Presidente a don Francisco de Saavedra, antiguo ministro de la Corona, confinado en Andalucía por la voluntad arbitraria del Príncipe de la Paz, se arrogó desde el principio una autoridad superior a la de cualquiera otra"115. Volvía Saavedra a protagonizar momentos graves de la historia de la crisis del reino. El bando del 6 de junio de 1808 la Suprema de Sevilla le declaró la guerra a Napoleón ${ }^{116}$. Saavedra, como hemos acotado, fue un entusiasta de América y del papel que pudo haber jugado su élite en la

114. Expediente personal de Francisco de Saavedra, 1798. Estado, leg. 3442, 8 (AHN).

115. Estudio preliminar de los diarios de Saavedra correspondientes a los años 1808-1810, en MORENO Alonso, Manuel, Francisco de Saavedra. La rebelión de las provincias de España. Los grandes días de la Junta Suprema de Sevilla, 1808-1810, Sevilla, Alfar, 2011, p. 26.

116. Ibid., p. 35. 
metrópoli. Esos sentimientos, durante los aciagos momentos de la ocupación francesa, resurgieron en otra dirección, cuando dice el sevillano pedir ayuda a la América española, e informar (el 15 de junio de 1808) cuanto antes, en los territorios del Nuevo Mundo, lo que ocurre en la península ${ }^{117}$.

La Junta Central, en buena medida, torpedeó los alcances de la sevillana, fracasando en sus objetivos. Un año más tarde, el 23 de enero de 1810, la Junta Central resolvió mudar operaciones a la Isla de León. Desde la nueva posición se pidió auxilio a figuras miembros de otras juntas provinciales. El ejército napoleónico había sido derrotado en Bailén en julio de 1808, con lo que los intrusos ya no contaban con Madrid, sin embargo, podían conquistar el sur, expresamente los últimos refugios de la insurrección, la Isla de León y Cádiz. Saavedra escribe sobre "el triste estado de la Monarquía" y la urgente necesidad de intervenir antes de la ruina total. La amenaza francesa no sólo se cernía sobre el suelo español, Napoleón mismo "se jactaría de haber consumado la conquista de España y resultarían los más fatales efectos en Indias donde sólo aguardaban este momento para declarar su independencia"118.

La comprometida situación vuelve a convocar a Saavedra a la cabeza de las circunstancias, como miembro ahora de la Regencia. Así pues, este sevillano era ahora, en el año de 1810, regente del reino. Como subraya Moreno Alonso, Saavedra estuvo "Omnipresente en todas las decisiones de los gobiernos de la España libre, desde el momento en que le aclamaron como Presidente de la Junta, él mismo llegó a confesar a Lady Holland, a su paso por Sevilla en 1809, que dos horas completas cada día, de cinco a siete, las dedicaba exclusivamente a estampar su firma"119.

Ese entusiasmo del héroe sevillano por lo americano, por el criollismo, lo volvemos a advertir en este diario de los días de la Junta Suprema de Sevilla. El 1 de julio, Saavedra escribe sobre la responsabilidad de la Junta respecto a

117. «La demora en la publicación de este manifiesto y el conflicto de los dictámenes inevitable en los cuerpos numerosos retardó a pesar de la actividad con que en todo procedía, la conclusión de los oficios para los varios dominios de Indias, dando noticias del inminente riesgo que amenazaba a la antigua España, manifestando la heroica resolución que habían tomado las provincias y las Juntas, e implorando los prontos auxilios de los hermanos de América para no sucumbir bajo el tiránico yugo del más escandaloso usurpador. Estaban ya concluidos y prontos los pliegos dirigidos a los virreyes, capitanes generales, Audiencias, gobernadores, prelados, ayuntamientos, y en esta tarde y noche se leyeron todos, operación que aún rápidamente ocupó más de cuatro horas (...) Allá se hallaban ya listos los barcos que los debían conducir a los varios parajes de aquellos vastos dominios con todas las precauciones necesarias para que no cayesen en poder de Napoleón, y aun para anticiparse a sus emisarios». Ibid., p. 135.

118. Ibid., p. 50.

119. Ibid., p. 68. 
los negocios y la marina con Indias; en relación a "tan vasto negociado", Saavedra escogió para tratar con América a Vicente Basadre "oficial real honorario y secretario del consulado de Veracruz (que se hallaba con licencia en España), hombre muy versado en los negocios de América y de Asia a donde había hecho varios viajes en la clase de comerciante y de comisionado por el gobierno"120; con estas anotaciones, volvemos a observar, aunque de manera circunstancial, indirecta, otra conexión sugerente con Caracas, pues fue Basadre el último intendente de Venezuela.

120. Ibid., p. 176. 